\title{
Pivotal role of Acitretin nanovesicular gel for effective treatment of psoriasis: ex vivo-in vivo evaluation study
}

This article was published in the following Dove Press journal: International Journal of Nanomedicine

\author{
Irhan Ibrahim Abu Hashim' \\ Noha Fawzy Abo El-Magd' \\ Ahmed Ramadan El-Sheakh ${ }^{2}$ \\ Mohammed Fawzy Hamed ${ }^{3}$ \\ Abd El-Gawad Helmy Abd \\ El-Gawad' \\ 'Department of Pharmaceutics, \\ Faculty of Pharmacy, Mansoura \\ University, Mansoura, Egypt; \\ 2Department of Pharmacology and \\ Toxicology, Faculty of Pharmacy, \\ Mansoura University, Mansoura, Egypt; \\ ${ }^{3}$ Department of Pathology, Faculty \\ of Veterinary Medicine, Mansoura \\ University, Mansoura, Egypt
}

\begin{abstract}
The goal of the current study was to explore the potential benefits of Acitretin (Act) nanovesicular gel as a prospective antipsoriatic topical delivery system counteracting the drug challenges in terms of its extremely low aqueous solubility, instability, skin irritation, and serious systemic adverse effects. Act-loaded niosomes were successfully developed, entirely characterized, and optimized. Further evaluation of the optimized formula was conducted regarding its stability and ex vivo cytotoxicity on different cell lines. The optimized niosomal vesicles were then incorporated in gel base matrix and investigated by sequential ex vivo (skin permeation and deposition) and in vivo (skin irritation and antipsoriatic activity using mouse tail model) experiments. The optimized Act-loaded niosomes (span 60:cholesterol molar ratio 1:1) were spherical in shape and exhibited the highest entrapment efficiency $(90.32 \pm 3.80 \%)$ with appropriate nanosize and zeta potential of $369.73 \pm 45.45 \mathrm{~nm}$ and $-36.33 \pm 1.80 \mathrm{mV}$, respectively. Encapsulation of the drug in the nanovesicles was further emphasized by differential scanning calorimetric and powder X-ray diffraction studies. After 3 months storage at $4 \pm 1^{\circ} \mathrm{C}$, the optimized formula preserved its stability. Act nano niosomal gel produced a remarkable enhanced ex vivo permeation profile up to $30 \mathrm{~h}$ and significant drug deposition in the viable epidermal-dermal layers compared with those of Act gel. The pronounced antipsoriatic activity of the medicated nano niosomes was proved ex vivo in HaCaT cells (a keratinocyte cell line). Topical application of Act nano niosomal gel to mouse tail model further established its distinct in vivo antipsoriatic superiority in terms of significantly higher orthokeratosis, drug activity, and reduction in epidermal thickness compared with the control and other gel formulations. Also, negligible skin irritation and better skin tolerability of Act nanovesicular gel were revealed by primary irritation index and histopathologic examination.
\end{abstract}

Keywords: Acitretin, nanovesicular gel, drug deposition, HaCaT cells, mouse tail model, antipsoriatic activity

\section{Introduction}

Human skin is one of the vital organs for drug targeting and administering of drugs in regard to diverse dermatologic disturbances such as alopecia, acne, skin cancer, tinea, and psoriasis. ${ }^{1}$

Psoriasis is a non-contagious, chronic, T-cell-mediated autoimmune inflammatory skin disease with a prevalence rate of $0.1-11.4 \%$ affecting millions of people worldwide. ${ }^{2-4}$ It is considered as a lifelong illness with erratic remissions and relapses. Hence, such a disease influences the patients psychologically, physically, socially, and financially. ${ }^{5,6}$ Clinically, the psoriatic disease is discriminated by sharply demarcated erythematous papules, as well as rounded plaques with silvery-white scales spread
Correspondence: Irhan Ibrahim Abu Hashim

Department of Pharmaceutics, Faculty of Pharmacy, Mansoura University,

El-Gomhoria Street, Mansoura

35516, Egypt

Tel +20 I0 9300848 I

Fax +20 502247496

Email irhanabuhashim@hotmail.com 
onto the extensor surfaces of the body. ${ }^{7}$ Itching, skin flaking, swelling, and pain are also associated symptoms of the disease. ${ }^{8}$ Histopathologic hallmarks of psoriasis comprise epidermal hyperproliferation, abnormal keratinocyte differentiation, acanthosis, angiogenesis with dermal capillaries dilation, and inflammatory cell infiltration in the skin layers. ${ }^{9}$ Despite the lack of clarity of the exact etiology of the disease, genetic, immunological, and environmental factors may be implicated..$^{10}$ Indeed, there are several lines of remedies either topically, phototherapeutically, systemically, or biologically administered based on the severity of the disease. However, none of them is ideal or safe. ${ }^{7}$ For instance, systemic treatment with methotrexate or cyclosporine is associated with hepatotoxicity and nephrotoxicity. ${ }^{11,12}$ Cardinal signs such as skin atrophy and hypopigmentation are experienced on topical application of steroids. Irritation and burning episodes are concomitant with other topical drugs. ${ }^{13,14}$ Likewise, some adverse effects have been coupled with phototherapy. ${ }^{15}$ In spite of the reported therapeutic efficacy of new biologics consisting of proteins and monoclonal antibodies, they are still more expensive than other remedies. ${ }^{16}$

The stratum corneum (SC) represents the main obstacle for topical treatment owing to its barrier properties. ${ }^{17}$ Specifically, in the case of psoriasis, the highly thickened and inflamed SC may restrain the antipsoriatic activity and efficacy of the drugs applied topically as conventional dosage forms: gel, cream, and ointment. ${ }^{18,19}$ Therefore, to overcome such challenges and limitations, intensive studies have focused on the development of safe effective targeted drug delivery systems. Among them, nanocarriers have emerged as superlative therapeutic approaches for multiple skin diseases involving psoriasis. $^{20}$

During the last decades, nanovesicular carriers attracted considerable attention for topical and transdermal drug delivery. In particular, non-ionic surfactant-based vesicles (niosomes) are one of the nanovesicles oriented to drug localization for treatment of numerous dermatologic disorders. They possess unique characteristics encompassing biodegradability, biocompatibility, nontoxicity, capability of loading both hydrophobic and hydrophilic drugs, enhanced skin penetration, and drug retention ability with negligible systemic absorption. From an industrial point of view, the low production cost, feasibility of handling, stability upon storage, availability, and purity of niosomal components led to their exploitation as an alternative to phospholipid-based vesicles. $^{21-26}$

Acitretin (Act), all-trans-Acitretin, is a second-generation retinoid approved by the US Food and Drug Administration for the systemic treatment of severe resistant psoriasis. ${ }^{27-29}$
Its oral administration is restricted by serious systemic side effects such as teratogenicity, hyperlipidemia, and hepatic toxicity. Also, cheilitis, hair loss, pyogenic granulomas, thinning of the nail plates, as well as dry and sticky skin are commonly associated mucocutaneous adverse effects. ${ }^{30}$ Hence, topical administration of Act is urgently required to provide a safer treatment regimen concurrently with increased drug local bioavailability at the action site, while minimizing the potential systemic exposure. Unfortunately, the physicochemical characteristics of the drug, such as its very low water solubility $(0.0729 \mathrm{mg} / \mathrm{mL})$, instability upon exposure to light, air, and heat, as well as skin irritation episodes accompanied with erythema, burning, and peeling of treated area, are great challenges for a topical formulation of Act. ${ }^{31-33}$ To address these tremendous problems, a few endeavors have been targeted toward the development of topical delivery systems for Act through complexation with cyclodextrin, ${ }^{34}$ and encapsulation in nanostructured lipid carriers $^{35}$ or chitin nanogel. ${ }^{36}$

Accordingly, this context encouraged us to devote this work to extensive ex vivo-in vivo investigations of Act nanovesicular gel in order to explore its pivotal role as a topical delivery system for effective treatment of psoriasis.

\section{Materials and methods Materials}

Act was kindly supplied by Sabaa Pharmaceutical Co. (Baltim, Egypt). Cholesterol (CH) and span 60 (sorbitan monostearate) were purchased from Alfa-Aesar (Karlsruhe, Germany). Hydroxypropylmethyl cellulose (HPMC 4K) was obtained from Dow Chem. Co. (Midland MI, USA). Propyl paraben and methyl paraben were supplied by AppliChem GmbH (Darmstadt, Germany). DMEM was obtained from Gibco Laboratories (Thermo Fisher Scientific, Waltham, MA, USA). Fetal bovine serum was purchased from Hyclone (Logan, UT, USA). Both MTT and dimethylsulfoxide were procured from Sigma-Aldrich (St Louis, MO, USA). All other chemicals and solvents used throughout the whole study were of analytical reagent grade.

\section{Preparation of Act-loaded niosomes}

Thin film hydration procedure was applied for niosome preparation $^{37}$ using different molar ratios of span 60 and $\mathrm{CH}$ as listed in Table 1. The drug, $\mathrm{CH}$, and span 60 were laid into a rounded bottomed flask of $100 \mathrm{~mL}$ capacity and dissolved in chloroform $(10 \mathrm{~mL})$. Thereafter, evaporation of the organic solvent was performed using a rotary evaporator (Buchi rotavapor, Flawil, Switzerland) under reduced pressure at $60^{\circ} \mathrm{C}$ until the formation of a thin dry film on 
Table I Composition of Act-loaded niosomal formulations

\begin{tabular}{ll}
\hline Formulation code & Span 60:CH (molar ratio) \\
\hline FI & $\mathrm{I}: \mathrm{I}$ \\
F2 & $\mathrm{I} .5: 1$ \\
F3 & $2: 1$ \\
F4 & $3: 1$ \\
F5 & $1: 1.5$ \\
F6 & $\mathrm{I}: 2$ \\
F7 & $\mathrm{I}: 3$ \\
\hline
\end{tabular}

Note: Each formulation contains 15 mg Act. Abbreviations: Act, Acitretin; $\mathrm{CH}$, cholesterol.

the inner wall of the flask. The flask was left in a desiccator under vacuum overnight to remove any traces of organic solvents. The film was then hydrated by the addition of $10 \mathrm{~mL}$ deionized water and agitated in a thermostatically controlled shaking water bath (Gallenkamp BKS-350, E.E.C.) at $55^{\circ} \mathrm{C}$ for $1 \mathrm{~h}$, till complete transformation of the thin lipid film into a milky suspension. The lipid film hydration was maintained above the gel-liquid transition temperature (Tc) of the sorbitan monoester surfactants..$^{38}$ The dispersion was then vortexed for $5 \mathrm{~min}$, followed by sonication for 20 min using a water bath sonicator (Abbot A Corporation, Princeton, NJ, USA). Finally, the niosomal dispersion was kept in a refrigerator overnight at $4^{\circ} \mathrm{C}$ for maturation of vesicles.

Separation of Act-loaded niosomes from the unentrapped drug was executed by cooling centrifugation (labofuge I; Heraeus, Christ, Gmbh osterode, Germany) at $19,922 \times g$ for $60 \mathrm{~min}$ at $4^{\circ} \mathrm{C}$. The isolated pellets were washed three times with deionized water under the same experimental conditions to ensure the removal of any unentrapped drug that might be present in the void volume between the niosomes. ${ }^{39}$

\section{Characterization of Act-loaded niosomes Entrapment efficiency}

Determination of the entrapped amount of Act was accomplished by lysis of vesicles with methanol. ${ }^{40}$ A sample of niosome dispersion $(100 \mu \mathrm{L})$ was mixed with $20 \mathrm{~mL}$ methanol in a well-closed bottle and then sonicated for $10 \mathrm{~min}$ in a bath-type sonicator (Abbot A Corporation) to obtain a clear solution. Act concentration in methanol was estimated spectrophotometrically at $353 \mathrm{~nm}$ (ultraviolet/visible spectrophotometer, V-530; JASCO, Tokyo, Japan) after suitable dilution using plain lysed niosomes as blank. The entrapment efficiency percentage, EE (\%), was calculated according to the following equation: ${ }^{41}$

$$
\mathrm{EE}(\%)=\frac{\text { Amount of entrapped drug }}{\text { Total amount of drug }} \times 100
$$

Particle size, polydispersity index, and zeta potential The particle size, polydispersity index (PDI) and zeta potential of Act-loaded niosomal dispersions were determined by dynamic light scattering using a zetasizer (ZEN 3600; Malvern Instruments Limited, Malvern, UK) after proper dilution with deionized water.

\section{Transmission electron microscope (TEM) studies}

The morphology of the optimized niosomal formulation (F1) was determined by TEM (JOEL 1010; JEOL Ltd, Tokyo, Japan). A drop of the niosomal dispersion, 10-fold diluted with deionized water, was placed on carbon-coated, 30-mesh copper grid for $1 \mathrm{~min}$ to permit the adherence of some niosomes to the carbon substrate. After removal of the remaining dispersion with a piece of filter paper, the grid was rinsed twice for a few seconds with deionized water, followed by application of a drop of uranyl acetate ( $2 \%$ aqueous solution) for $1 \mathrm{~s}$. The excess solution was drained off with a piece of filter paper. Finally, the sample was air dried, and examined at $160 \mathrm{kV}$ with TEM. ${ }^{42}$

\section{Differential scanning calorimetric (DSC) studies}

The thermal properties of pure Act, span $60, \mathrm{CH}$, their physical mixture, as well as the lyophilized plain and optimized Act-loaded niosomal formulation (F1) were investigated using DSC (Shimadzu, DSC-60 with TA-60 WS thermal analyzer; Rigaku, Tokyo, Japan) calibrated with indium as the standard. Four milligrams of powdered sample in a hermetically closed aluminum pan was scanned at a rate and temperature range of $10^{\circ} \mathrm{C} / \mathrm{min}$ and $20-350^{\circ} \mathrm{C}$, respectively, under nitrogen as the purge gas.

\section{Powder X-ray diffraction (PXRD) studies}

The PXRD patterns of the optimized medicated niosomal formulation (F1), its individual components, physical mixture, and corresponding plain niosomes were determined by means of X-ray diffractometer (FW 1700 X-ray diffractometer; Philips, Amsterdam, the Netherlands). The analysis was carried out under the following circumstances: irradiation with monochromatized $\mathrm{Cu} \mathrm{K} \alpha$ radiation $\left(\lambda=1.542 \mathrm{~A}^{\circ}\right)$, current $(30 \mathrm{~mA})$, and voltage $(40 \mathrm{kV})$ from $2^{\circ}$ to $40^{\circ}$ at $2 \theta$ angle.

\section{Ex vivo skin permeation study for different niosomal formulations}

Before conducting the experiment, the hair of the abdominal side of male albino rats weighing 150-200 $\mathrm{g}$ was removed using an animal hair clipper. After $24 \mathrm{~h}$, the skin was visually inspected carefully for its integrity. The rats were then 
sacrificed and the full-thickness abdominal skin was excised followed by removal of the adhering fat and visceral tissues. Eventually, the skin was rinsed thoroughly with distilled water and soaked overnight in $\mathrm{NaCl} 0.9 \%$ solution at a refrigerated temperature $\left(4 \pm 1^{\circ} \mathrm{C}\right)$, before the experiment.

Ex vivo permeation experiments for Act in propylene glycol (control) and different niosomal formulations were performed using vertical Franz diffusion cells with a diameter of $3 \mathrm{~cm}$ and a surface area of $7.07 \mathrm{~cm}^{2}$. The excised rat skin was mounted on the donor half-cell with the SC side toward the donor, while the dermal side faced the receptor compartment which contained a $100 \mathrm{~mL}$ hydroalcoholic solution of PBS $\mathrm{pH} 7.4 /$ methanol $(1: 1 \mathrm{v} / \mathrm{v})$ and was maintained at $37 \pm 0.5^{\circ} \mathrm{C}$ using a thermostatically controlled water bath (Gallenkamp BKS-350, E.E.C.) agitated at $100 \mathrm{rpm}$ (Figure S1). The hydroalcoholic solution $(1: 1 \mathrm{v} / \mathrm{v})$, as a receptor medium, was used to allow quantitative determination of Act because of its poor aqueous solubility $(0.0729 \mathrm{mg} / \mathrm{L}) .{ }^{36}$ The niosomal formulation or the drug suspended in propylene glycol was placed on the skin in the donor half-cell which was sealed with parafilm. To hinder exposure to light, the cell was covered with aluminum foil. At predetermined time intervals $(0.5,1,2,3,4,5,6,8,10,24$, and $30 \mathrm{~h})$, samples of $3 \mathrm{~mL}$ were withdrawn from the receptor compartment and substituted with an equivalent volume of fresh hydroalcoholic solution to maintain sink conditions. The withdrawn samples were filtered by $0.45 \mu \mathrm{m}$ membrane filter and analyzed spectrophotometrically at $353 \mathrm{~nm}$ (ultraviolet/visible spectrophotometer, V-530; JASCO).

\section{Skin permeation parameters}

The following skin permeation parameters were calculated:

- $Q_{30 \mathrm{~h}}$ : The cumulative amount of Act permeating the rat skin after $30 \mathrm{~h}$ per unit area $\left(\mu \mathrm{g} / \mathrm{cm}^{2}\right)$.

- $J_{\text {ss }}$ : Steady-state flux which was calculated from the slope of the linear portion of the cumulative amount of drug permeated per unit surface area-time curve $\left(\mu \mathrm{g} / \mathrm{cm}^{2} / \mathrm{h}\right)$ according to the following equation: ${ }^{43}$

$$
J_{\mathrm{ss}}=\frac{\mathrm{dQ}}{\mathrm{dt}} \mathrm{A}
$$

- $K_{\mathrm{p}}$ : Permeability coefficient $(\mathrm{cm} / \mathrm{h})$ was then calculated with the succeeding equation: ${ }^{44}$

$$
K_{\mathrm{p}}=\frac{\frac{\mathrm{dQ}}{\mathrm{dt}} \mathrm{A}}{\mathrm{C}_{\mathrm{D}}}
$$

where $\mathrm{A}$ is the area of the skin, $\mathrm{dQ} / \mathrm{dt}$ the slope of the linear region for the plot of Act amount in the receiver chamber vs time $(\mu \mathrm{g} / \mathrm{h})$, and $\mathrm{C}_{\mathrm{D}}$ is the donor concentration $(\mu \mathrm{g} / \mathrm{mL})$.

- $\mathrm{ER}_{\text {flux }}$ : Enhancement ratio of flux was calculated according to the following equation: ${ }^{45}$

$$
\mathrm{ER}_{\text {flux }}=\frac{\text { Flux of Act-loaded niosomal formulation }}{\text { Flux of free drug }}
$$

\section{Storage stability study}

The optimized niosomal formulation (F1) was subjected to stability study by storage at refrigerated $\left(4 \pm 1^{\circ} \mathrm{C}\right)$ and room $\left(25 \pm 1^{\circ} \mathrm{C}\right)$ temperatures in screw-capped amber glass vials for a period of 3 months. ${ }^{46}$ Evaluation parameters such as particle size, PDI, EE (\%), and drug retention (\%) were determined before and after 1, 2, and 3 months of the storage period as mentioned above.

\section{Preparation of Act gel and Act niosomal gel}

The optimum niosomal formulation (F1) was incorporated into a gel base of HPMC $(2 \% \mathrm{w} / \mathrm{w})$ to ameliorate its rheological properties with subsequent increase in the residence time and therapeutic effect of the drug at the site of application as well as improved patient acceptability and applicability. In this study, two gel formulations were prepared: Act gel (containing the free drug) and Act niosomal gel (containing the optimum niosomal formulation, F1).

The specified weight of HPMC $(2 \% \mathrm{w} / \mathrm{w})$ was sprinkled on a small amount of distilled water and left to hydrate overnight. Then, the drug $(0.1 \% \mathrm{w} / \mathrm{w})$ was levigated with propylene glycol $(10 \% \mathrm{w} / \mathrm{w})$, added to the gel, followed by addition of glycerol $(10 \% \mathrm{w} / \mathrm{w})$ and other ingredients (methyl and propyl parabens; 0.05\% w/w for each) with stirring using a magnetic stirrer. Ultimately, distilled water was used to adjust the final weight of the gel to $100 \mathrm{~g}$. In the case of Act niosomal gel preparation, the same procedure was adopted by incorporation of niosomal dispersion (F1) equivalent to the specified concentration of Act in the gel formulation.

\section{Evaluation parameters of Act gel and Act niosomal gel Appearance and color}

The gel formulations were visually inspected for their appearance, homogeneity, color, and existence of any lumps or aggregates. 


\section{$\mathrm{pH}$ measurement}

The $\mathrm{pH}$ of the gels was measured using a digital $\mathrm{pH}$ meter (Beckman Instruments, Fullerton, CA, USA) ${ }^{47}$

\section{Viscosity measurement}

Viscosity measurements of the gels were determined using a cone and plate rotary viscometer (Haake Inc., Vreden, Germany). The temperature was maintained at $37 \pm 0.5^{\circ} \mathrm{C}$. One gram of each formulation was placed on the viscometer plate with a diameter of $2.9 \mathrm{~cm}$. The torque value "S" was determined and the speed value " $\mathrm{N}$ " was maintained at $256 \mathrm{rpm}$. The following equation was applied for calculation of the viscosity:

$$
\eta=\frac{\mathrm{GS}}{\mathrm{N}}
$$

where $\eta$ is the viscosity in $\mathrm{mPa} s(\mathrm{mPa} \mathrm{s}=1 \mathrm{cP}), \mathrm{G}$ is the instrumental factor $(14,200 \mathrm{mPa}$ s/scale grade $\mathrm{min}), \mathrm{S}$ is the torque (scale grade), and $\mathrm{N}$ is the speed (rpm).

\section{Drug content}

Two grams of the gel were dissolved in $25 \mathrm{~mL}$ methanol in a stoppered volumetric flask and sonicated for $15 \mathrm{~min}$ to extract the drug. The resulting solution was then filtered and suitably diluted with methanol. Finally, analysis of Act concentration was performed via ultraviolet/visible spectrophotometer at $353 \mathrm{~nm}$ against methanol as a blank.

\section{Ex vivo skin permeation study for Act gel and Act niosomal gel}

The ex vivo permeation study was carried out for Act gel and Act niosomal gel as previously described in the "Ex vivo skin permeation study for different niosomal formulations" section. Also, the skin permeation parameters were calculated as mentioned above.

\section{Skin deposition study}

After completion of the ex vivo permeation study for the gel formulations, the rat skin samples were taken from the diffusion cells, and their surfaces were gently rinsed three times with PBS ( $\mathrm{pH}$ 7.4) to eliminate the residual Act on the surfaces, and then dried using filter paper. The collected skin samples were divided into two sets; one set was used to determine the total amount of Act deposited in the whole skin layers, while the second one was used for drug determination in the SC and viable epidermis/dermis (VED). Briefly, the SC was removed by consecutive tape-stripping procedure with 10 adhesive tapes (Scotch tape ${ }^{\circledR}, 3 \mathrm{M}$, Saint Paul, MN, USA), followed by separation of VED. The whole skin layers, SC tape strips, or VED were cut into small pieces and soaked for $24 \mathrm{~h}$ in screw-capped amber glass bottles containing $20 \mathrm{~mL}$ methanol. Then, an ultrasound bath was used for shaking the methanolic samples four times for half an hour each to ensure extraction of the entire Act deposited in the skin pieces. ${ }^{48}$ After centrifugation and filtration, the amount of the drug in the supernatants was analyzed spectrophotometrically at $353 \mathrm{~nm}$. The same procedure was carried out for the skin deposition study using blank gel. This filtered extract was used as the blank solution to diminish any interference from rat skin components.

\section{Kinetic analysis of release data}

Ex vivo permeation data of the optimized niosomal formulation (F1), Act gel, and Act niosomal gel were fitted to numerous kinetic models such as zero order, first order, and Higuchi. ${ }^{49}$ Furthermore, Korsmeyer-Peppas kinetic model was used to investigate the proper drug release mechanism according to the equation $\mathrm{mt} / \mathrm{m} \infty=\mathrm{kt}^{\mathrm{n}}$, where $\mathrm{mt} / \mathrm{m} \infty$, $\mathrm{k}$, $\mathrm{t}$, and $\mathrm{n}$ express the fraction of drug released, the kinetic constant, the release time, and the diffusional exponent for drug release (the slope of $\log \mathrm{mt} / \mathrm{m} \infty$ vs $\log$ time curve), respectively. ${ }^{50,51}$

\section{Cytotoxicity study on $\mathrm{L} 929$ and $\mathrm{HaCaT}$ cell lines}

In this study, two cell lines, namely, mouse dermal fibroblast (L929) and human epidermal keratinocytic cells (HaCaT, a model of epidermal hyperproliferation in psoriasis), were selected for assessment of the cytotoxic effect of free Act, Act-loaded niosome (F1), and its corresponding plain niosomal formulation by MTT colorimetric assay. Briefly, the cells were obtained from the American Type Culture Collection through VACSERA (Cairo, Egypt), and cultured in DMEM containing $100 \mathrm{U} / \mathrm{mL}$ of penicillin and $100 \mu \mathrm{g} / \mathrm{mL}$ of streptomycin, as well as supplemented with $10 \%(\mathrm{v} / \mathrm{v})$ fetal bovine serum at $37^{\circ} \mathrm{C}$ in a humidified $5 \% \mathrm{CO}_{2}$ and $95 \%$ air atmosphere. The cells were seeded in 96-well plates (100 $\mu \mathrm{L} /$ well, containing $1.0 \times 10^{4}$ cells/well) and incubated for $24 \mathrm{~h}$ at $37^{\circ} \mathrm{C}$. Then, the medium was gently aspirated and the cells were treated with $100 \mu \mathrm{L}$ of tested samples in various concentrations ranging from 0.1 to $100 \mu \mathrm{g} / \mathrm{mL}$. After $24 \mathrm{~h}$ incubation period, the wells were washed with PBS and treated with MTT solution $(5 \mathrm{mg} / \mathrm{mL})$ for a $4 \mathrm{~h}$ incubation period at $37^{\circ} \mathrm{C}$ to allow formazan crystal formation from reduction of MTT by the mitochondria of viable cells. The crystals were then dissolved by addition of dimethylsulfoxide to each well and shaking for $15 \mathrm{~min}$. The OD of each well 
was measured at $570 \mathrm{~nm}$ using a microplate reader (Dynatech, Melville, NY, USA). The following equation was utilized to calculate the cell viability percentage:

$$
\text { Cell viability }(\%)=\frac{\mathrm{OD}_{570} \text { sample }}{\mathrm{OD}_{570} \text { control }} \times 100
$$

where $\mathrm{OD}_{570}$ sample is the $\mathrm{OD}_{570}$ of treated cells and $\mathrm{OD}_{570}$ control is the $\mathrm{OD}_{570}$ of untreated cells.

In addition, the half-maximal inhibitory concentration $\left(\mathrm{IC}_{50}\right)$ values referring to the drug concentration required to kill $50 \%$ of cells relative to the untreated cells were determined. ${ }^{52,53}$

\section{In vivo studies}

\section{Animals}

Male Wistar albino rats and adult Swiss albino mice were employed for in vivo skin irritation and antipsoriatic activity studies, respectively. The animals were caged individually 1 week before conducting the experiments for their acclimation under standard laboratory conditions set at $25 \pm 1^{\circ} \mathrm{C}, 55 \pm 5 \%$ relative humidity, and $12 \mathrm{~h}$ light $/ 12 \mathrm{~h}$ dark photoperiod cycles with free access to water and diet. The experimental protocols were done in full compliance with the ethical guidelines of the scientific committee of the Faculty of Pharmacy, Mansoura University, Egypt. The research was also approved by the committee.

\section{Skin irritation study}

Skin irritation potential of different gel formulations was assessed by visual inspection of erythema and edema (primary irritation index [PII]) as well as histopathologic examination.

\section{PII test}

The hair on the back of the rats (200-230 g) over an area of $8.1 \mathrm{~cm}^{2}$ was shaved using an electric hair clipper $24 \mathrm{~h}$ prior to beginning the experiment. The rats were divided into five groups ( $n=6$ per group) and topically treated with $1.5 \mathrm{~g}$ of each formula once daily for 7 consecutive days as follows:

- Group 1: untreated (control)

- Group 2: Plain gel

- Group 3: Zarotex gel (0.1\% w/w; commercial product)

- Group 4: Act gel $(0.1 \% \mathrm{w} / \mathrm{w})$

- Group 5: Act niosomal gel $(0.1 \% \mathrm{w} / \mathrm{w})$

The sites of application were visually inspected for skin erythema and edema that were scored at 1,3 , and
7 days according to Draize scale. ${ }^{54}$ Scoring of erythema and edema between 0 and 4 was based on the degree of severity of skin reactions from no response to a severe response.

PII was calculated according to the following equation:

$$
\mathrm{PII}=\frac{\left\{\begin{array}{c}
\text { Sum of erythema grade } \\
\text { at } 1 / 3 / 7 \text { days }
\end{array}+\begin{array}{c}
\text { Sum of edema grade } \\
\text { at } 1 / 3 / 7 \text { days }
\end{array}\right\}}{\text { Number of animals }}
$$

Categorization of the irritation degree as negligible (PII =0-0.4), slight (PII =0.5-1.9), moderate (PII =2-4.9), or severe (PII $=5-8)$ irritation was based on the PII values. ${ }^{55}$

\section{Histopathologic examination}

Finally, after calculation of PII, the rats were sacrificed, and the treated skin samples were excised, then fixed with $10 \%$ buffered formaldehyde solution, embedded in paraffin, sectioned into $4 \mu \mathrm{m}$ thickness using microtome (SM2400; Leica Microsystems, Cambridge, England), stained with H\&E, and examined microscopically by a light microscope (Olympus, Tokyo, Japan) for any histopathologic changes.

\section{Antipsoriatic activity study using mouse tail model}

The mouse tail model was previously reported as one of the accepted psoriasis models for screening the antipsoriatic activity of the drugs. ${ }^{56-60}$ In fact, the adult mouse tail normally possesses a parakeratotic differentiation which is considered the hallmark of psoriasis.

In this study, adult Swiss albino mice (25-30 g) were divided into five groups ( $\mathrm{n}=6$ per group) as follows:

- Group 1: untreated (control)

- Group 2: Plain gel

- Group 3: Zarotex gel $(0.1 \% \mathrm{w} / \mathrm{w}$; commercial product)

- Group 4: Act gel $(0.1 \% \mathrm{w} / \mathrm{w})$

- Group 5: Act niosomal gel $(0.1 \% \mathrm{w} / \mathrm{w})$

The gel formulations ( $0.5 \mathrm{~g}$ each) were topically applied on the proximal half of the tail, $\sim 2 \mathrm{~cm}$ long, and then the treated part was covered with plastic tube and fixed with adhesive tape. The protocol of once-daily treatment of mice tails was continued for 4 consecutive weeks. Two hours after the last treatment, the animals were sacrificed. Thereafter, the processed tails were fixed with $10 \%$ buffered formaldehyde solution, embedded in paraffin, longitudinally sectioned into $5 \mu \mathrm{m}$ thickness, and stained using H\&E. Finally, the sections 
were microscopically examined for histopathologic evaluation parameters including the following:

- Orthokeratosis (\%): It is defined as the number of scale regions with a continuous granular layer which is counted and expressed as a percentage of the total number of scale regions per section. It was calculated according to the following equation: 56

Orthokeratosis $(\%)=\frac{\text { Granular layer per scale }}{\text { Whole scale length }} \times 100$

- Drug activity (\%): It is defined by the increase in the orthokeratosis (\%) regions and calculated as follows: ${ }^{59}$

Drug activity $(\%)=\frac{\begin{array}{c}\text { Mean OK of } \\ \text { treated group }\end{array}-\text { control group }}{100-\text { Mean OK of control group }} \times 100$

where $\mathrm{OK}$ is orthokeratosis.

- Epidermal thickness: It was calculated by measuring the distance between the beginning of the horny layer and the dermo-epidermal junction using ImageJ software. Five measurements per animal were estimated and the mean of different mice was calculated. ${ }^{59}$

\section{Statistical analysis}

One-way analysis of variance pursued by Tukey-Kramer multiple comparisons test was used at a significance level of $p<0.05$ for statistical analysis of the data using Instat GraphPad Prism software (version 5.00; Graphpad software, San Diego, CA, USA).

\section{Results and discussion \\ Preparation and characterization of different niosomal formulations}

Initially, preliminary experiments concerning the effects of diverse variables such as organic solvent, drug amount, rotation speed of the flask, hydration medium and time, as well as sonication time were investigated to establish the vesicle formation with appropriate size and highest $\mathrm{EE} \%$. According to the initial survey, the most adequate conditions for vesicle preparation were Act at a dose of $15 \mathrm{mg}$, chloroform as an organic solvent, and deionized water as a hydration medium. The vesicles were formed after hydration for $1 \mathrm{~h}$ and sonication for $20 \mathrm{~min}$.

\section{Entrapment efficiency}

The capability of niosomes to entrap a significant amount of Act is essential for its targeted use for topical management of psoriasis. The effect of different molar ratios of span $60: \mathrm{CH}$ on the EE\% of Act in niosomes is presented in Table 2.

A significant difference $(p<0.05)$ was found in $\mathrm{EE} \%$ among all the niosomal formulations. The results demonstrated that gradual incorporation of $\mathrm{CH}$ in the niosomal formulations was concomitant with a marked increase in the $\mathrm{EE} \%$ of Act, with the maximum value of $90.32 \pm 3.80 \%$ at 1:1 span $60: \mathrm{CH}$ molar ratio (F1). These data could be explained by the fact that $\mathrm{CH}$ has the ability to stop the gel to liquid phase transition of surfactant bilayers, intercalate into the bilayers, and cement their leaking spaces. Therefore, these factors result in conferring more rigidity and stability to the bilayers with subsequent prevention of leakage of the entrapped drug. ${ }^{61-63}$ Additionally, span 60 exhibited the maximum $\mathrm{EE} \%$ of the drug at this molar ratio owing to its long saturated alkyl chain that decreased the amount of $\mathrm{CH}$ required to form niosomes. ${ }^{64}$

On the other hand, further increase in $\mathrm{CH}$ content revealed a significant decrease $(p<0.05)$ in the $\mathrm{EE} \%$ of Act-loaded niosomes from $90.32 \pm 3.80 \%$ to $68.63 \pm 2.79 \%$ for the formulations F1 and F7, respectively. This could be attributed to disruption of the regular bilayered structure of the vesicles upon addition of $\mathrm{CH}$ beyond a particular concentration, leading to loss of drug entrapment levels. ${ }^{65}$ Moreover, competition between higher amounts of $\mathrm{CH}$ and the drug for the packing spaces within the bilayers might prompt exclusion of the drug as amphiphiles assemble into the vesicles. ${ }^{66,67}$

\section{Particle size, PDI, and zeta potential}

Table 2 illustrates the particle size, PDI, and zeta potential of different Act-loaded niosomes. The PDI values of all the prepared niosomes were in the range of $0.1-0.5$, therefore pointing to a narrow size distribution and good homogeneity.

The particle size data elucidated gradual enlargement in the niosomal vesicle size associated with the increment in span 60 in the formulation from $221.60 \pm 24.24$ to

Table 2 Characterization of Act-loaded niosomal formulations

\begin{tabular}{lllll}
\hline $\begin{array}{l}\text { Formulation } \\
\text { code }\end{array}$ & PS $(\mathbf{n m})$ & PDI & ZP $(\mathbf{m V})$ & EE (\%) \\
\hline FI & $369.73 \pm 45.45$ & $0.095 \pm 0.03$ & $-36.33 \pm 1.80$ & $90.32 \pm 3.80$ \\
F2 & $505.30 \pm 73.98$ & $0.141 \pm 0.03$ & $-37.83 \pm 0.31$ & $86.64 \pm 2.58$ \\
F3 & $607.83 \pm 69.26$ & $0.226 \pm 0.06$ & $-39.17 \pm 0.58$ & $82.17 \pm 4.02$ \\
F4 & $784.43 \pm 18.01$ & $0.467 \pm 0.12$ & $-41.20 \pm 0.36$ & $78.50 \pm 5.53$ \\
F5 & $279.67 \pm 20.13$ & $0.179 \pm 0.04$ & $-20.77 \pm 0.81$ & $80.32 \pm 3.19$ \\
F6 & $265.93 \pm 28.38$ & $0.225 \pm 0.05$ & $-21.50 \pm 1.14$ & $77.30 \pm 2.45$ \\
F7 & $221.60 \pm 24.24$ & $0.212 \pm 0.06$ & $-27.23 \pm 1.16$ & $68.63 \pm 2.79$
\end{tabular}

Note: Each value represents the mean $\pm S D(n=3)$.

Abbreviations: Act, Acitretin; EE, entrapment efficiency; PDI, polydispersity index; PS, particle size; ZP, zeta potential. 
784.43土18.01 nm for F7 and F4, respectively. Similar findings were also observed by Zaki et al in the preparation of diacerein-loaded niosomes. ${ }^{68}$

The target of our study was the topical delivery of Act to avert its systemic serious side effects. Previously, Verma et $\mathrm{a}^{69}$ reported that vesicles larger than $600 \mathrm{~nm}$ did not deliver the encapsulated drug into deeper skin layers. To some extent, these vesicles might remain within the SC forming a lipid layer upon drying, which might strengthen the barrier properties of SC to a large extent. Accordingly, the formulation of Act-loaded niosomes with particle size smaller than $600 \mathrm{~nm}$ was vital to assure the penetration and deposition of Act into the deeper skin layers. The data published by Gupta et $\mathrm{al}^{70}$ elicited that different vesicular systems of capsaicin, including niosomes, with smaller particle size (172-368 nm) were convenient for penetration through the deeper layers of the skin with potentiated antipsoriatic activity.

As summarized in Table 2, zeta potential values for Actloaded niosomes ranged from $-20.77 \pm 0.81$ to $-41.20 \pm 0.36 \mathrm{mV}$, indicating that the prepared niosomes have adequate charge to prohibit their aggregation due to electric repulsion. Generally, zeta potential values around $\pm 30 \mathrm{mV}$ represent stable nanoparticulate systems because of the electrical repulsion between these particles. ${ }^{71}$

Consequently, the optimum niosomal formulation which would be therapeutically effective for topical delivery of Act as an antipsoriatic agent, as indicated by suitable particle size, PDI, zeta potential and maximum EE\%, was F1. Hence, F1 was selected for further elaborate investigations.

\section{TEM studies}

The TEM micrograph of the niosomal formula (F1) revealed that the vesicles were spherical in shape with a definite wall and core, nonaggregated, and nanometric in size. Furthermore, the mean particle size of the niosomes measured by TEM micrographs was in good concordance with that recorded by the zeta sizer (Figure 1).

\section{DSC studies}

Figure 2 shows the DSC thermograms of pure Act, span 60, $\mathrm{CH}$, physical mixture, medicated niosomes (the optimum formula; F1), and their corresponding plain ones.
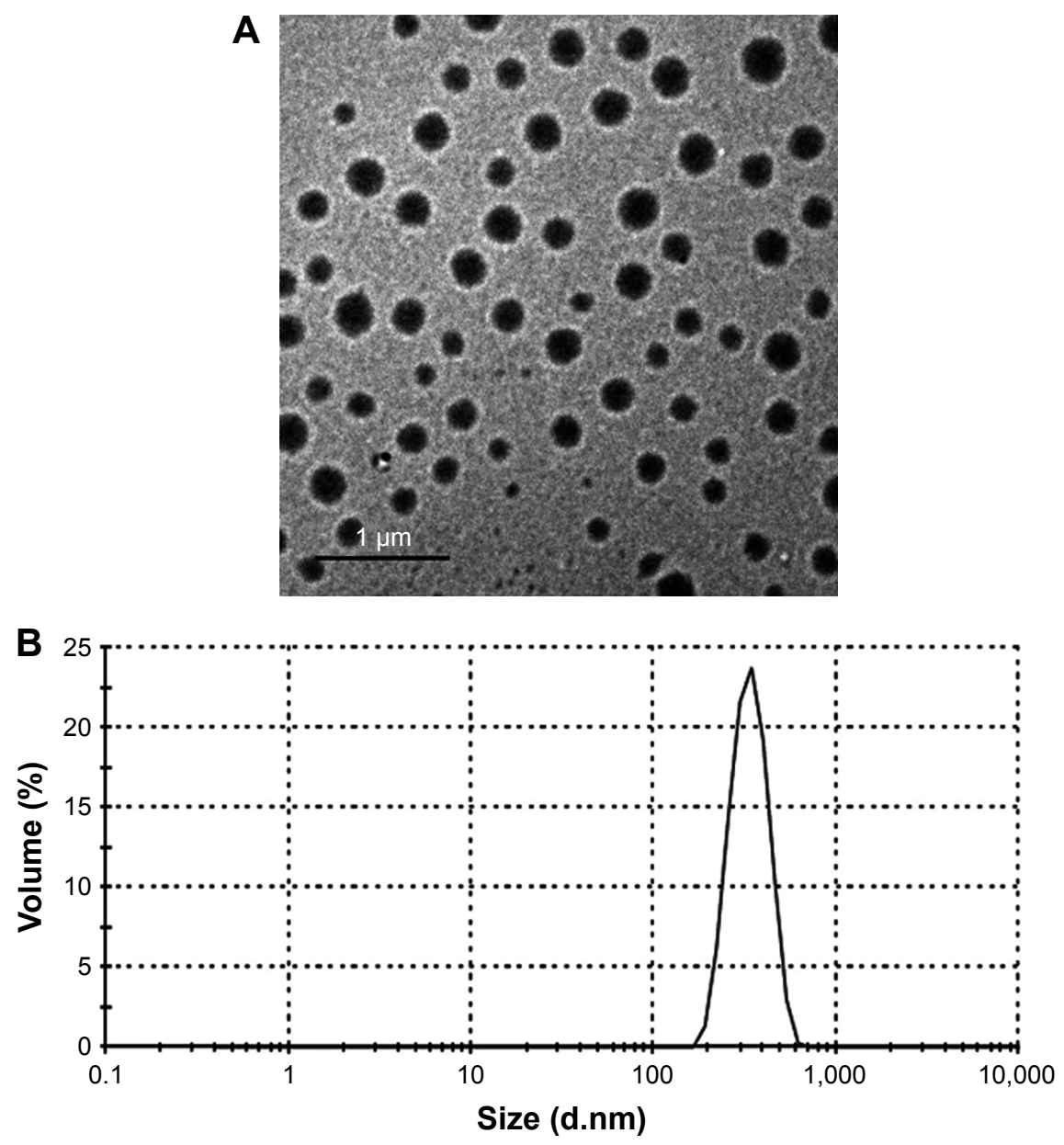

Figure I (Continued) 


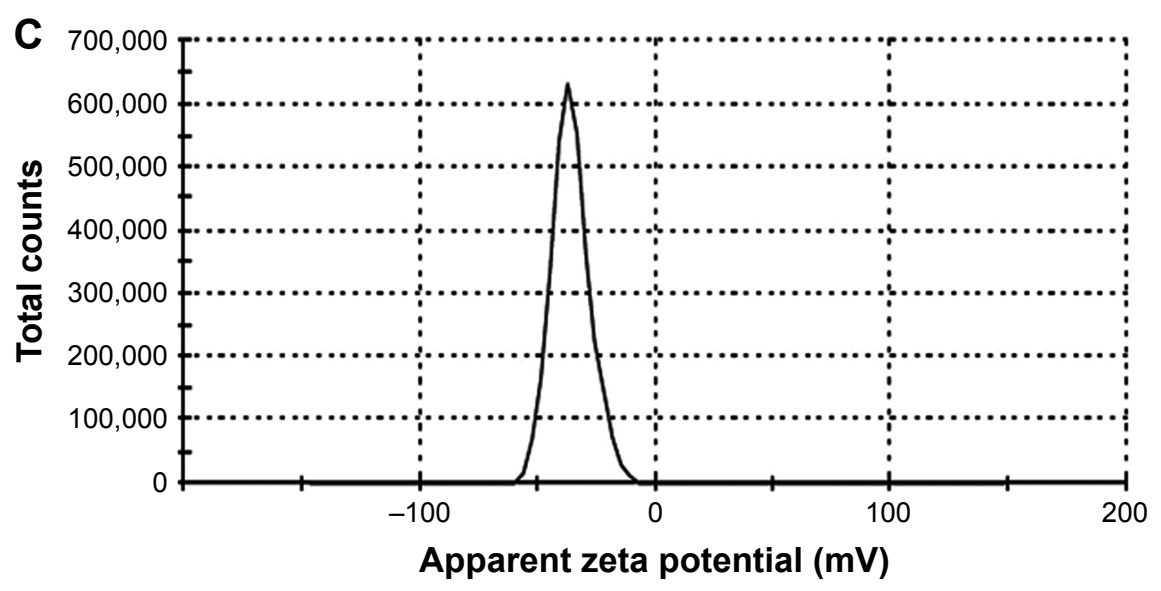

Figure I TEM image, size, and zeta potential distribution curves of Act-loaded niosome (FI). Note: (A) TEM image, (B) size distribution curve, and (C) zeta potential distribution curve. Abbreviations: Act, Acitretin; TEM, transmission electron microscope.

Thermograms of Act, span 60, and $\mathrm{CH}$ exhibited sharp endothermic peaks at $225.09^{\circ} \mathrm{C}, 58.42^{\circ} \mathrm{C}$, and $150.18^{\circ} \mathrm{C}$, respectively. The distinctive endothermic peaks of the individual components were evident in the physical mixture. In the case of plain niosomes, an apparent alteration in span 60 phase transition temperature from $58.42^{\circ} \mathrm{C}$ to $41.30^{\circ} \mathrm{C}$ was noticed with clear modulations in enthalpy as well as a considerable peak broadening. Interestingly, the DSC thermogram of Act-loaded niosomes clarified vanishing of the melting endothermic peak of Act and shifting of the major

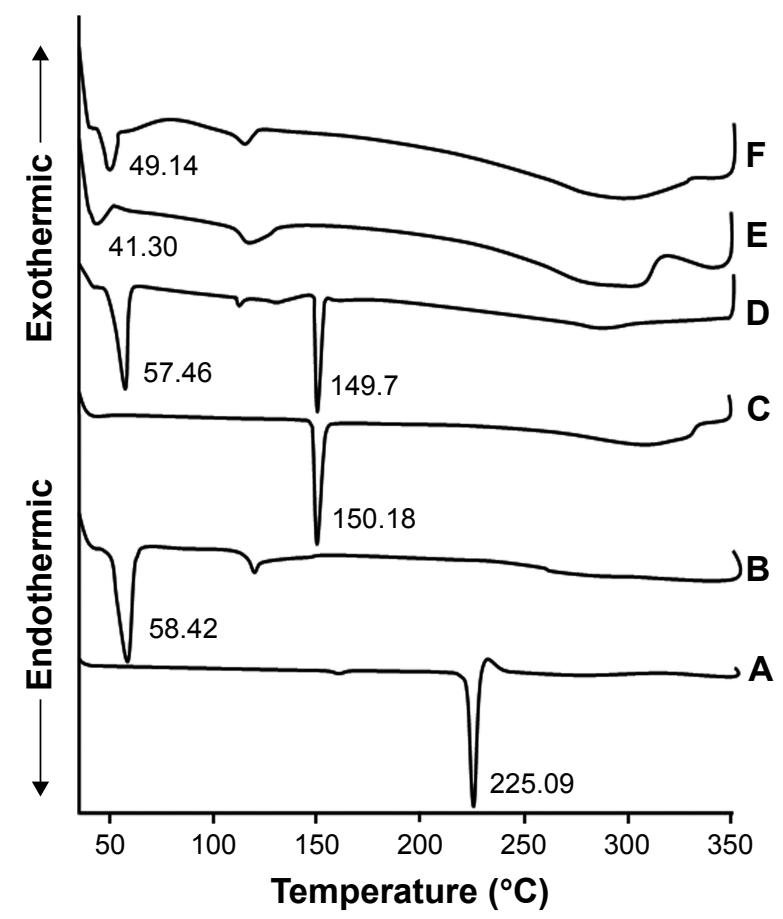

Figure 2 DSC thermograms.

Note: (A) Act, (B) Span 60, (C) CH, (D) physical mixture, (E) plain niosome, and (F) Act-loaded niosome (FI).

Abbreviations: Act,Acitretin; $\mathrm{CH}$, cholesterol; DSC, differential scanning calorimetry. endothermic peak of span 60 to $49.14^{\circ} \mathrm{C}$ in a similar manner to that observed in plain niosomes.

The remarkable absence of the endothermic peak of Act, in the case of medicated niosomes, might be imputed to the presence of the drug in the amorphous state and its entrapment in the lipid bilayers of the niosomal system. ${ }^{72-75}$

\section{PXRD studies}

From the PXRD results (Figure 3), it was obvious that pure Act displayed highly crystalline nature with characteristic peaks at $2 \theta$ of $8.90^{\circ}, 11.99^{\circ}, 23.68^{\circ}$, and $24.21^{\circ}$, whereas span 60 and $\mathrm{CH}$ showed prominent diffraction peaks at $2 \theta$ of $21.41^{\circ}$ and $5.16^{\circ}$, respectively. In the physical mixture, the crystalline peaks of span 60 and $\mathrm{CH}$ were clearly evident. On the other hand, the Act-loaded niosomes (F1) showed disappearance of the principal peaks of Act, span 60 , and $\mathrm{CH}$. Hence, this might indicate the conversion of the

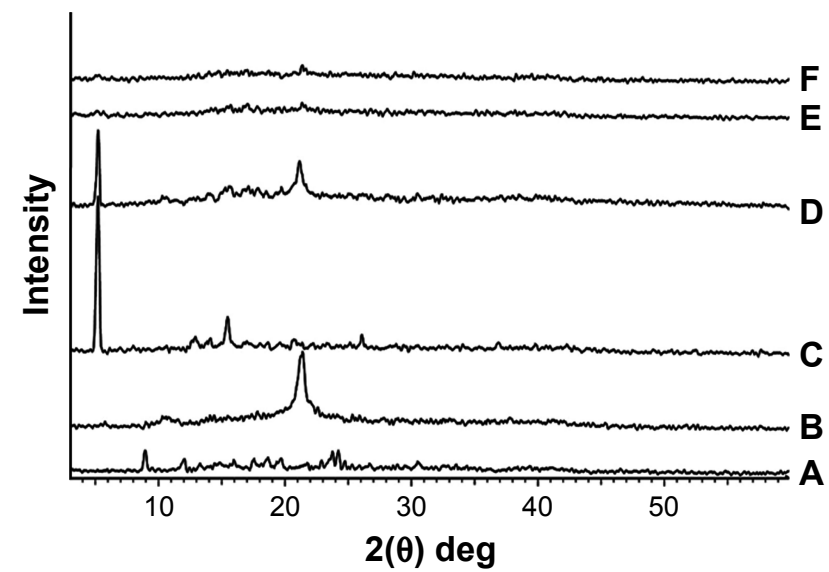

Figure 3 PXRD patterns.

Note: (A) Act, (B) Span 60, (C) CH, (D) physical mixture, (E) plain niosome, and (F) Act-loaded niosome (FI).

Abbreviations: Act, Acitretin; $\mathrm{CH}$, cholesterol; PXRD, powder X-ray diffractometry. 


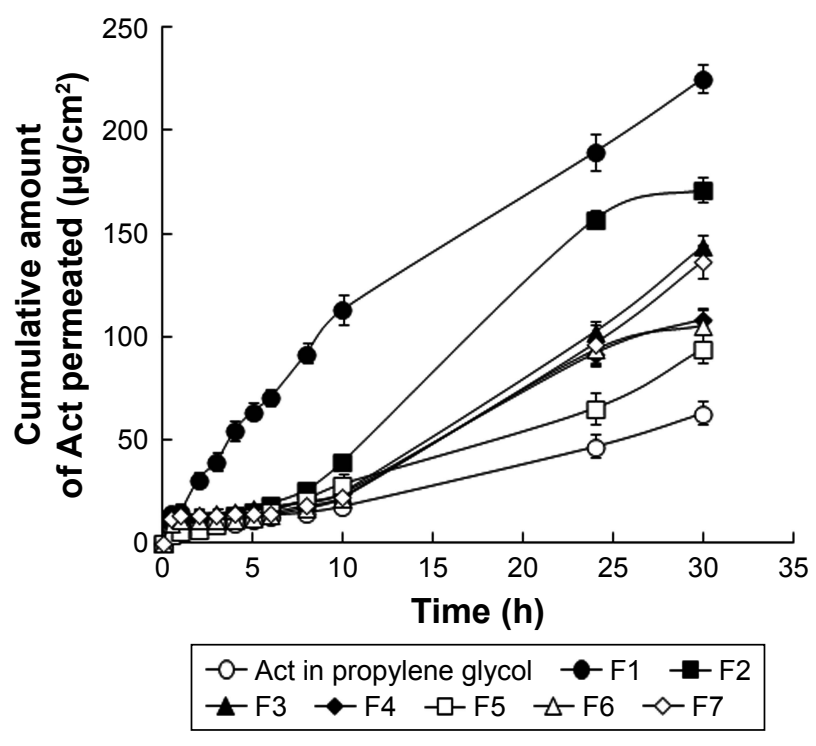

Figure 4 Ex vivo skin permeation profiles of Act from different niosomal formulations.

Note: Each point represents the mean \pm SD $(n=3)$.

Abbreviation: Act, Acitretin.

native crystalline form of Act to amorphous state and its entrapment in the vesicular system. A similar pattern was previously reported for other drugs loaded in niosomal systems. ${ }^{46,74}$

\section{Ex vivo skin permeation study for different niosomal formulations}

In order to estimate the potential of the developed niosomes for skin targeting and permeation ability, an ex vivo skin permeation study was performed using vertical Franz diffusion cells.

As depicted in Figure 4, the ex vivo permeation profiles of Act from different niosomal formulae through the excised rat skin were compared with that of the control (drug in propylene glycol). The cumulative amount of Act permeated per unit of surface area from niosomal vesicles or control formula was determined during $30 \mathrm{~h}$ experiments.
The permeation rate was in the order Act in propylene glycol $<$ F5 $<$ F $6<$ F $4<\mathrm{F} 7<\mathrm{F} 3<\mathrm{F} 2<\mathrm{F} 1$. This behavior could be explained on the basis of increasing $\mathrm{CH}$ content in niosomal formulations that resulted in stabilization of the bilayers, prevention of drug leakage, and retardation of its permeation. ${ }^{61-63}$ On the contrary, increasing the $\mathrm{CH}$ content beyond a certaing limit may lead to disruption of the regular bilayered structure of vesicular membranes with subsequent increase in the permeation rate of the drug. ${ }^{65}$

As illustrated in Table 3, it could be concluded that the niosomal formulations showed significant difference $(p<0.05)$ in all the permeation parameters vs the control. Notably, the formula F1 exhibited prominent superiority because of its highest permeation parameters including $Q_{30 \mathrm{~h}}\left(225.40 \pm 6.78 \mu \mathrm{g} / \mathrm{cm}^{2}\right), J_{\mathrm{ss}}\left(7.07 \pm 0.15 \mu \mathrm{g} / \mathrm{cm}^{2} / \mathrm{h}\right), K_{\mathrm{p}}$ $\left(4.11 \times 10^{-3} \mathrm{~cm} / \mathrm{h}\right)$, and $\mathrm{ER}_{\text {flux }}(3.75 \pm 0.08)$.

\section{Storage stability study}

In this study, the stability of F1 after storage at refrigerated and room temperatures was assessed with regard to particle size, $\mathrm{PDI}, \mathrm{EE} \%$, and drug retention $\%$ for 3 successive months as listed in Table 4.

Compared with the initial data of the evaluation parameters, no significant change was recorded in the case of storage at refrigerated temperature throughout the storage period. In contrast, after 3 months, destabilization of the formula was found at room temperature based on significant $(p<0.05)$ enlargement in particle size $(683.83 \pm 43.89 \mathrm{~nm})$, and drug leakage with less $\mathrm{EE} \%(71.30 \pm 6.31 \%)$ and drug retention \% (78.95 $\pm 6.96 \%)$. Notably, comparative statistical analysis (refrigerated temperature vs room temperature) highlighted the distinguished stabilization effect of the refrigeration condition at different time intervals on the tested niosomal formula. As reported, regidization of niosomal membrane and, subsequently, enhanced drug retention could account for this effect. ${ }^{76}$ Unlike refrigeration, destabilization at room

Table 3 Ex vivo skin permeation parameters of Act from different niosomal formulations across the excised rat skin after $30 \mathrm{~h}$

\begin{tabular}{lllll}
\hline Formulation code & $\mathrm{Q}_{30 \mathrm{~h}}\left(\mu \mathrm{g} / \mathbf{c m}^{2}\right)$ & $J_{\mathrm{ss}}\left(\mu \mathrm{g} / \mathbf{c m}^{2} / \mathbf{h}\right)$ & $K_{\mathrm{p}}(\mathbf{c m} / \mathbf{h}) \times \mathbf{I 0}^{-3}$ & $\mathbf{E R}_{\text {flux }}$ \\
\hline Act in propylene glycol (control) & $63.19 \pm 5.48$ & $1.88 \pm 0.17$ & $1.09 \pm 0.00$ & - \\
FI & $225.40 \pm 6.78^{* * * *}$ & $7.07 \pm 0.15^{* * * *}$ & $4.11 \pm 0.00^{* * * *}$ & $3.75 \pm 0.08^{* *}$ \\
F2 & $171.10 \pm 6.08^{*}$ & $6.11 \pm 0.15^{*}$ & $3.55 \pm 0.00^{*}$ & $3.25 \pm 0.08$ \\
F3 & $143.72 \pm 5.39 *$ & $4.44 \pm 0.16^{*}$ & $2.58 \pm 0.00^{*}$ & $2.36 \pm 0.08$ \\
F4 & $108.48 \pm 4.70^{*}$ & $3.54 \pm 0.15^{*}$ & $2.06 \pm 0.00^{*}$ & $1.89 \pm 0.08$ \\
F5 & $93.99 \pm 6.62^{*}$ & $2.95 \pm 0.22^{*}$ & $1.71 \pm 0.00^{*}$ & $1.57 \pm 0.12$ \\
F6 & $105.63 \pm 8.5 I^{*}$ & $3.55 \pm 0.23^{*}$ & $2.07 \pm 0.00^{*}$ & $1.89 \pm 0.12$ \\
F7 & $136.42 \pm 7.90^{*}$ & $4.20 \pm 0.23^{*}$ & $2.44 \pm 0.00^{*}$ & $2.23 \pm 0.12$ \\
\hline
\end{tabular}

Notes: Each value represents the mean $\pm S D(n=3)$. $* p<0.05$ vs control; $* * p<0.05 \mathrm{FI}$ vs other formulations.

Abbreviations: Act, Acitretin; ER, enhancement ratio; $J_{s s}$, steady state flux; $K_{\mathrm{p}}$, permeability coefficient; $Q_{30}$, cumulative amount that permeated after $30 \mathrm{~h}$. 
Table 4 Stability study data of Act-loaded niosomal formulation ( $\mathrm{FI})$ after storage at refrigerated and room temperatures

\begin{tabular}{|c|c|c|c|c|c|c|c|}
\hline \multirow[t]{2}{*}{ Parameters } & \multicolumn{4}{|c|}{ Refrigerated temperature $\left(4 \pm 1^{\circ} \mathrm{C}\right)$} & \multicolumn{3}{|c|}{ Room temperature $\left(25 \pm 1^{\circ} \mathrm{C}\right)$} \\
\hline & Initial & I month & 2 months & 3 months & I month & 2 months & 3 months \\
\hline PS (nm) & $369.73 \pm 45.45$ & $421.49 \pm 24.39 *, \neq$ & $443.66 \pm 32.87^{* \# \#}$ & $498.06 \pm 45.03^{* \wedge}$ & $475.37 \pm 38.76^{*}$ & $528.19 \pm 26.04 *$ & $683.83 \pm 43.89 *$ \\
\hline PDI & $0.095 \pm 0.03$ & $0.340 \pm 0.10$ & $0.346 \pm 0.11$ & $0.306 \pm 0.11$ & $0.365 \pm 0.11$ & $0.443 \pm 0.07^{*}$ & $0.409 \pm 0.15^{*}$ \\
\hline $\mathrm{EE}(\%)$ & $90.32 \pm 3.80$ & $87.40 \pm 2.32$ & $85.00 \pm 3.96$ & $82.88 \pm 4.33^{\wedge}$ & $82.33 \pm 3.95$ & $77.60 \pm 4.87^{*}$ & $71.30 \pm 6.31^{*}$ \\
\hline Drug retention (\%) & $100.00 \pm 0.00$ & $96.77 \pm 2.56$ & $94.11 \pm 4.39$ & $91.77 \pm 4.79^{\wedge}$ & $91.16 \pm 4.38$ & $84.63 \pm 3.91^{*}$ & $78.95 \pm 6.96 *$ \\
\hline
\end{tabular}

Notes: Each value represents the mean $\pm S D(n=3)$. ${ }^{*} p<0.05$ vs initial measurements; ${ }^{\ddagger} p<0.05$ refrigerated temperature vs room temperature after I-month storage; ${ }^{\#} p<0.05$ refrigerated temperature vs room temperature after 2-month storage; ${ }^{1} p<0.05$ refrigerated temperature vs room temperature after 3 -month storage.

Abbreviations: Act, Acitretin; EE, entrapment efficiency; PDI, polydispersity index; PS, particle size.

temperature with respect to drug leakage could be explained by the possibility of phospholipid bilayer oxidation and hydrolysis, as well as fluidity of the vesicular membrane. Additionally, the tendency for particle adhesion and aggregation could result in their size enlargement. ${ }^{76}$ Thus, the developed Act-loaded niosome (F1) should be kept at refrigerated temperature $\left(4 \pm 1^{\circ} \mathrm{C}\right)$.

\section{Evaluation parameters of Act gel and Act niosomal gel}

The Act gel and Act niosomal gel were evaluated for their appearance, color, $\mathrm{pH}$, viscosity, and drug content. The results are demonstrated in Table 5.

\section{Appearance and color}

The Act gel was yellow, homogeneous, and translucent due to the yellow color of the drug itself, while the Act niosomal gel was yellowish white, homogeneous, and opaque, related to the color of the niosome.

\section{$\mathrm{pH}$ measurement}

The $\mathrm{pH}$ values of both gels were in the range of 6.18-6.23, which is physiologically acceptable and suitable for topical as well as transdermal application. ${ }^{77}$

\section{Viscosity measurement}

The viscosity of Act niosomal gel $(1,386.72 \pm 9.85 \mathrm{cP})$ was higher than that of Act gel $(1,164.84 \pm 8.65 \mathrm{cP})$ as the niosome

Table 5 Evaluation parameters of different gel formulations

\begin{tabular}{lll}
\hline Parameters & Act gel & Act niosomal gel \\
\hline Appearance & Translucent & Opaque \\
& homogeneous gel & homogeneous gel \\
Color & Yellow & Yellowish white \\
$\mathrm{pH}^{*}$ & $6.23 \pm 0.23$ & $6.18 \pm 0.16$ \\
Viscosity (cP)* & $1,164.84 \pm 8.65$ & $1,386.72 \pm 9.85$ \\
Drug content (\%)* & $98.78 \pm 0.73$ & $97.67 \pm 0.64$ \\
\hline
\end{tabular}

Note: *Each value represents the mean \pm SD $(n=3)$. Abbreviation: Act, Acitretin. itself augmented the HPMC gel viscosity. Importantly, the incorporation of the niosomal formulation into the gel base could enhance its permeability and, particularly, its stability via retardation of vesicle fusion and aggregation, hence allowing better topical delivery. ${ }^{78,79}$

\section{Drug content}

The drug content of Act gel and Act niosomal gel was $98.78 \pm 0.73 \%$ and $97.67 \pm 0.64 \%$, respectively. The data demonstrated that deviation of the drug content from the originally added drug complies with the United States Pharmacopeia official requirements. ${ }^{80}$ Besides, the small values of the SD represent a uniform distribution of Act within the gel formulations.

\section{Ex vivo skin permeation and skin deposition studies for gel formulations}

Compared with Act gel, Act niosomal gel showed a remarkable enhanced ex vivo permeation profile over a period of $30 \mathrm{~h}$ (Figure 5 ) as assessed by significantly $(p<0.05)$ greater skin permeation parameters with 3.16-, 3.34-, and 3.31-fold increase in $Q_{30 \mathrm{~h}}, K_{\mathrm{p}}$, and $\mathrm{ER}_{\text {flux }}$, respectively, as summarized in Table 6.

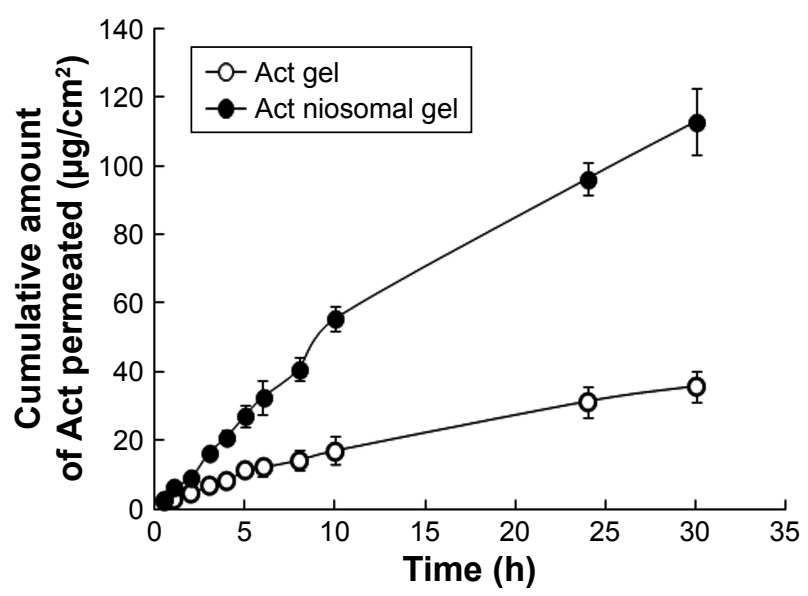

Figure 5 Ex vivo skin permeation profiles of Act from different gel formulations. Note: Each point represents the mean \pm SD $(n=3)$.

Abbreviation: Act, Acitretin. 
Table 6 Ex vivo skin permeation parameters of Act from different gel formulations across the excised rat skin after $30 \mathrm{~h}$

\begin{tabular}{lllll}
\hline Formulation & $\mathbf{Q}_{30 \mathrm{~h}}\left(\mu \mathrm{g} / \mathrm{cm}^{2}\right)$ & $J_{\mathrm{ss}}\left(\mu \mathrm{g} / \mathrm{cm}^{2} / \mathbf{h}\right)$ & $K_{\mathrm{p}}(\mathbf{c m} / \mathbf{h}) \times \mathbf{I 0}^{-3}$ & $\mathbf{E R}_{\text {flux }}$ \\
\hline Act gel & $35.66 \pm 4.6 \mathrm{I}$ & $1.13 \pm 0.14$ & $0.65 \pm 0.00$ & - \\
Act niosomal gel & $112.81 \pm 9.87^{*}$ & $3.73 \pm 0.25^{*}$ & $2.17 \pm 0.00^{*}$ & $3.31 \pm 0.22$ \\
\hline
\end{tabular}

Notes: Each value represents the mean $\pm S D(n=3)$. ${ }^{*}<0.05$ vs Act gel using Student's $t$-test (unpaired $t$-test).

Abbreviations: Act, Acitretin; ER, enhancement ratio; $J_{\text {ss }}$, steady state flux; $K_{\mathrm{p}}$, permeability coefficient; $Q_{30}$, cumulative amount that permeated after $30 \mathrm{~h}$.

After $30 \mathrm{~h}$ ex vivo permeation experiments for niosomal and non-niosomal Act gels, the amounts of the drug deposited in the SC and VED were determined (Figure 6). It was evident that the drug accumulated in the skin layers in the case of Act niosomal gel was significantly higher $(p<0.05)$ than that of Act gel. Specifically, Act niosomal gel delivered a maximum amount of the drug in the VED $\left(330.86 \pm 5.32 \mu \mathrm{g} / \mathrm{cm}^{2}\right)$, which represents the vital layers for keratinocytes' overproliferation in the case of psoriasis.

The profound enhancement effect of Act niosomal gel in skin permeation and deposition of the drug could be related to numerous combined reasons enumerated as follows: ${ }^{40,61,81-83}$ 1) the nanosize of the vesicles; 2) efficient adsorption and fusion of niosomes onto the skin surface may result in a high local concentration gradient of the drug and, subsequently, its direct transfer from the niosomal vesicles to the skin with higher flux values; 3) the role of non-ionic surfactant as a penetration enhancer in reducing the barrier function of SC through fluidization of the intercellular lipid bilayers; 4) the vesicles' lipid bilayers represent a rate-limiting membrane barrier for the drug; and 5) the lipid-rich environment of the SC may act as a depot for lipophilic drugs such as Act in the SC intercellular spaces, conferring slow permeation of

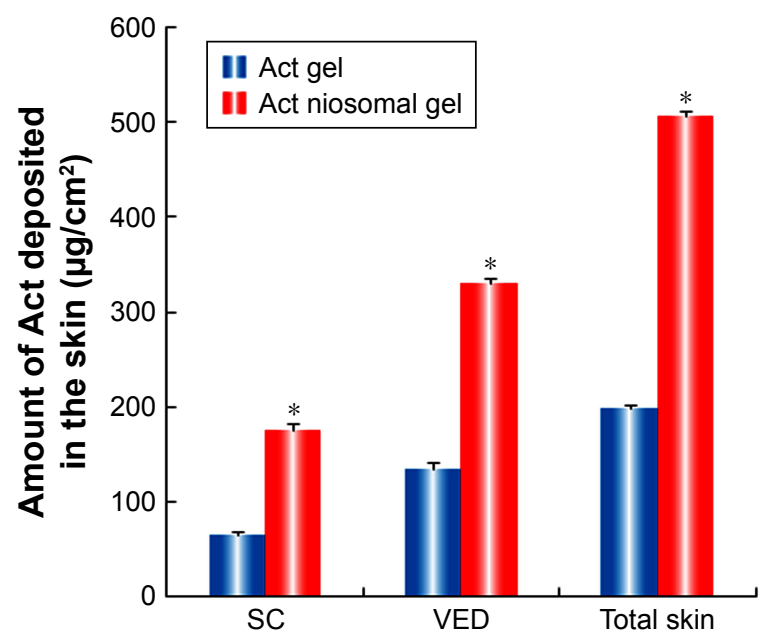

Figure 6 Ex vivo skin deposition profiles of Act from different gel formulations. Notes: Each value represents the mean \pm SD $(n=3)$. ${ }^{*} p<0.05$ vs Act gel using Student's $t$-test (unpaired $t$-test).

Abbreviations: Act, Acitretin; SC, stratum corneum; VED, viable epidermis/dermis. the drug into the lower viable epidermis, which represents the original site for the development of psoriatic disease.

\section{Kinetic analysis of release data}

To explore the drug release mechanism, the release kinetic parameters and correlation coefficients $\left(r^{2}\right)$ were calculated for the investigated Act niosomal dispersion (F1) and both gel formulations (Table 7). The ex vivo release data for all formulae displayed the Higuchi kinetic model (diffusion-controlled release) as the most fitted model with the highest $r^{2}$. These results were consistent with previous research findings. ${ }^{84,85}$ Further analysis of our release data was performed using Korsmeyer-Peppas equation to get more insight on other implicated drug release mechanisms based on the diffusional exponent ( $\mathrm{n}$ ) values: $\mathrm{n}<0.5$ (Fickian), $0.5<\mathrm{n}<1$ (non-Fickian), $\mathrm{n}>1$ (erosion-mediated release). The analyzed data indicated that the (n) values were in the range between 0.5 and 1, proposing the non-Fickian (anomalous) release mechanism for the drug (couple of erosion and diffusion)..$^{50}$

\section{Cytotoxicity study on L929 and HaCaT cell lines}

Figure 7 shows the ex vivo cytotoxicity of free Act, plain niosomes, and optimized Act-loaded niosomes (F1) in the concentration range of $0.1-100 \mu \mathrm{g} / \mathrm{mL}$ in $\mathrm{L} 929$ and $\mathrm{HaCaT}$ cell lines, assessed using MTT assay test. The viability of both cell lines treated with plain niosomes was reasonably maintained. The safety profile of plain niosomes toward different cell lines has been reported earlier ${ }^{86-89}$ Regarding L929 cells, the viability was reduced for both free Act and Act-loaded niosomes in a concentration-dependent manner; however, a relative improvement in cell viability of the drug was achieved after loading in niosomal vesicles (Figure 7A). These outcomes were in accordance with the cytotoxicity data published by Divya et al $^{36}$ for Act, either free or entrapped in chitin nanogel. On the other hand, a specific cytotoxicity of the drug was recorded toward the highly proliferative HaCaT cells $\left(\mathrm{IC}_{50}=15.352 \pm 0.387 \mu \mathrm{g} / \mathrm{mL}\right)$, which was further augmented after encapsulation in the nano niosomal carrier $\left(\mathrm{IC}_{50}=3.448 \pm 0.383 \mu \mathrm{g} / \mathrm{mL}\right.$; Figure $\left.7 \mathrm{~B}\right)$. The potentiated 
Table 7 Kinetic analysis of the release data of Act from niosomal dispersion and different gel formulations

\begin{tabular}{|c|c|c|c|c|c|c|c|}
\hline \multirow[t]{3}{*}{ Formulation } & Zero order & First order & \multirow[t]{3}{*}{ Higuchi model } & \multirow[t]{3}{*}{$\begin{array}{l}\text { Release } \\
\text { mechanism }\end{array}$} & \multirow{2}{*}{\multicolumn{2}{|c|}{$\begin{array}{l}\text { Korsmeyer- } \\
\text { Peppas } \\
\text { Diffusional } \\
\text { exponent }\end{array}$}} & \multirow[t]{3}{*}{$\begin{array}{l}\text { Drug release } \\
\text { mechanism }\end{array}$} \\
\hline & \multirow{2}{*}{\multicolumn{2}{|c|}{ Correlation coefficient $\left(r^{2}\right)$}} & & & & & \\
\hline & & & & & $\left(r^{2}\right)$ & (n) & \\
\hline $\begin{array}{l}\text { Act niosomal } \\
\text { dispersion (FI) }\end{array}$ & 0.976 & 0.983 & 0.990 & Diffusion & 0.985 & 0.725 & Non-Fickian \\
\hline Act gel & 0.978 & 0.979 & 0.990 & Diffusion & 0.991 & 0.706 & Non-Fickian \\
\hline Act niosomal gel & 0.979 & 0.982 & 0.985 & Diffusion & 0.991 & 0.904 & Non-Fickian \\
\hline
\end{tabular}

Abbreviation: Act, Acitretin.

antiproliferative activity of Act-loaded niosomes could be possibly correlated to the cellular uptake of niosomes by endocytosis that enables a prompt internalization in the cytoplasm and release of the drug to interact more readily with its target, leading to cell death. ${ }^{86,90}$ The released Act from the niosomal carrier exerts its effect primarily through binding to nuclear receptors, namely, retinoic acid receptors and retinoic $\mathrm{X}$ receptors, and modulating the gene expression of numerous proteins implicated in the pathogenesis of psoriasis. ${ }^{91}$ Also, the drug indirectly inhibits particular genes which regulate the pathologic criteria of the disease such as proliferation of epidermal layers, angiogenesis, and inflammation. ${ }^{92,93}$

Despite the lack of clarity of the specific mechanism of Act, numerous hypotheses have focused on two ways of action. The first way comprises the modification of the metabolism and action of endogenous retinoids. ${ }^{94,95}$ This hypothesis was tested by Armstrong et $\mathrm{al}^{96}$ who demonstrated that Act, in a concentration-dependent manner, might reduce all-trans retinoic acid metabolism by binding to cellular retinoic acidbinding proteins, therefore conferring a greater opportunity for binding of all-trans retinoic acid to nuclear receptors. The second way involves the inclusive immune regulation of the inflammatory molecules and cells entangled in psoriasis, ${ }^{95,97}$ specifically T helper 1 and T helper 17 cells. $^{98-100}$

\section{In vivo studies}

Based on the aforementioned in vitro characterization, ex vivo and stability data, the formula F1 was chosen as the optimized one for further in vivo evaluation studies.

\section{Skin irritation study}

Skin irritation study was carried out as an essential prerequisite for topical formulations to assess the potential of any
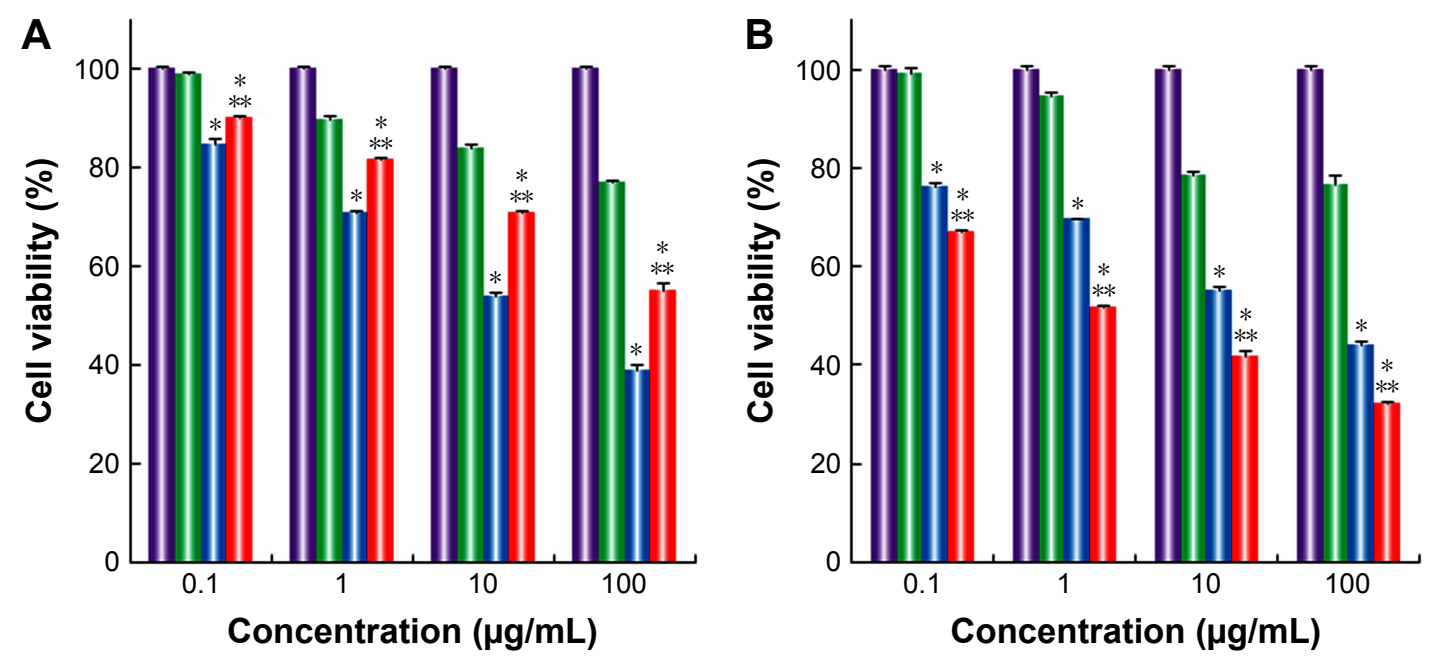

II Control II Plain niosome II Act II Act-loaded niosome (F1)

Figure 7 Ex vivo cytotoxicity studies performed by MTT assay.

Notes: (A) L929 cell line. (B) HaCaT cell line. Each value represents the mean $\pm S D(n=3) . * p<0.05$ vs plain niosome corresponding to the same concentration, $* * p<0.05$ vs Act corresponding to the same concentration.

Abbreviations: Act, Acitretin; HaCaT, human epidermal keratinocytic cells; L929, mouse dermal fibroblast cells. 

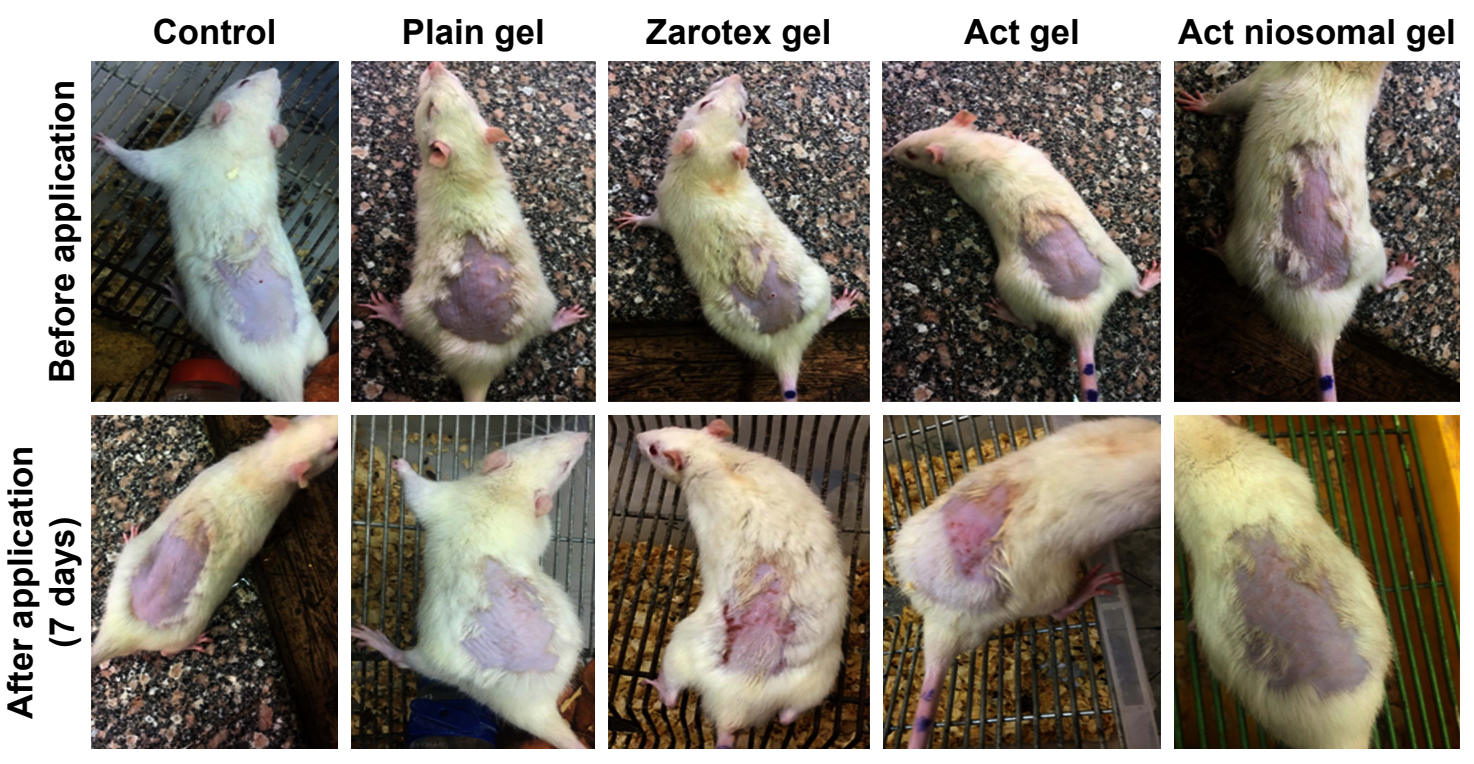

Figure 8 Monitoring progression of irritation before and after (7 days) topical application of different gel formulations. Abbreviation: Act, Acitretin.

irritation tendency to the skin, and hence ensuring patient compliance upon application.

One of the prime drawbacks accompanying Act therapy is skin irritation, which robustly limits its applicability and acceptability among patients. ${ }^{31,33}$ Therefore, it is warranted to develop a topical delivery system of Act capable of diminishing these irritation episodes implicated in Act therapy. To the best of our knowledge, no commercial topical products of Act are available until now. Thus, in this study, the commercial product zarotex gel $(0.1 \% \mathrm{w} / \mathrm{w})$ was selected for comparison because it contains tazarotene, a third-generation retinoid, that is effective in topical treatment of psoriasis and simultaneously exhibits remarkable irritation as the side effect. ${ }^{101,102}$

\section{PII test}

The progression of irritation upon cumulative topical applications of different gel formulations for 7 days to rats was macroscopically monitored (Figure 8) and expressed as PII values (Figure 9). The data demonstrated that zarotex gel and Act gel resulted in severe (PII $=5.1$ ) and moderate $(\mathrm{PII}=3.2)$ skin irritation, respectively. In sharp contrast, the PII value for Act niosomal gel was 0.0, indicating no skin irritation potential.

\section{Histopathologic examination}

The results of PII study were further ascertained by histopathologic examination, which is an indicator of any ultrastructural changes in the skin layers (Figure 10).

Photomicrograph of skin treated with zarotex gel showed necrosis of the epidermis with crust formation of the overlying superficial layer (arrow) and dilated blood capillaries in the underlying dermis (arrowhead). In the case of Act gel, the skin exhibited degenerative changes of the prickle cell layer and status spongiosus formation (arrow) with normal dermis and skin appendages. On the contrary, no histopathologic alteration was observed in the case of skin treated with Act niosomal gel, as indicated by normal structure of the epidermis and underlying dermis with normal skin appendages, which was comparable to that of the untreated control and plain gel formulation.

According to the above-mentioned irritation study data, the pronounced effect of Act niosomal gel in preventing the irritation tendency of the drug could be ascribed to the entrapment of Act in the bilayer of the niosomal system leading

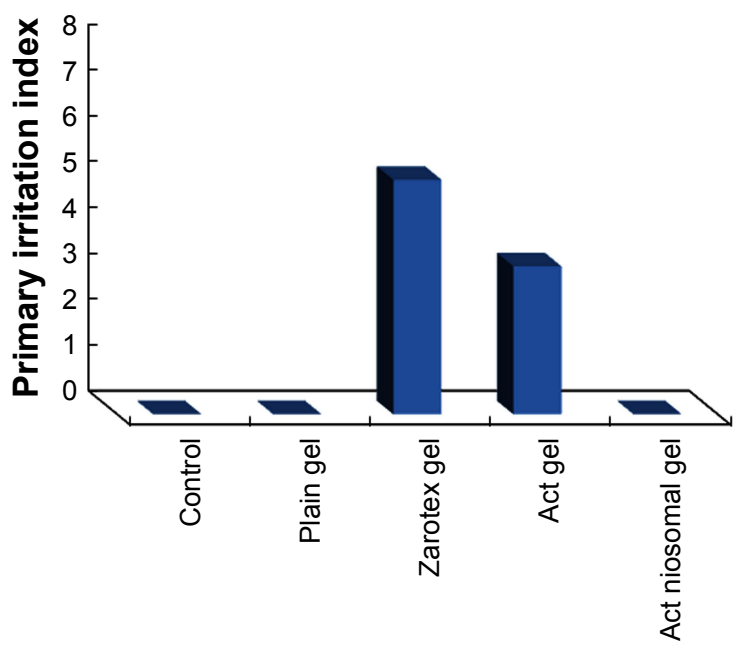

Figure 9 Primary irritation index after topical application of different gel formulations for 7 days $(n=6)$.

Abbreviation: Act, Acitretin. 


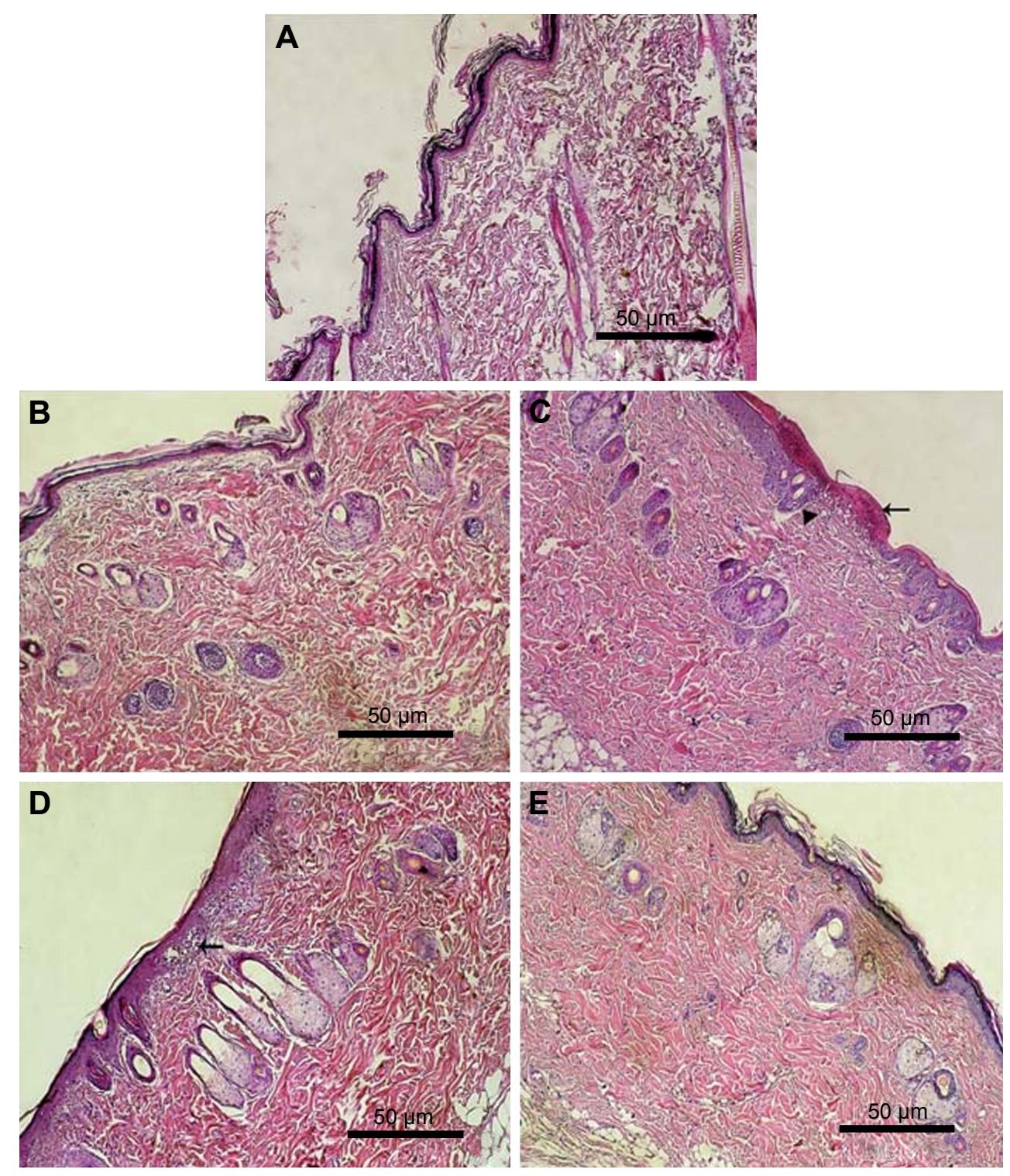

Figure 10 Photomicrographs of histopathologic examination of skin irritation after topical application of different gel formulations for 7 days.

Notes: (A) Control rat skin, (B) plain gel, (C) zarotex gel, (D) Act gel, and (E) Act niosomal gel. H\&E (I00x). Photomicrograph of skin treated with zarotex gel showed necrosis of the epidermis with crust formation of the overlying superficial layer (arrow) and dilated blood capillaries in the underlying dermis (arrowhead). Photomicrograph of skin treated with Act gel exhibited degenerative changes of the prickle cell layer and status spongiosus formation (arrow) with normal dermis and skin appendages. Abbreviation: Act, Acitretin.

to avoidance of direct contact of its acidic functional group $(-\mathrm{COOH})$, the trigger factor for irritation episodes, with the SC of the skin.

Analogus findings were experienced by other researchers who demonstrated the pivotal role of niosomal gel in improving the topical delivery of adapalene (third-generation topical retinoid) and capsaicin with a concomitant reduction of their irritation effect. ${ }^{70,103}$ Previously, Agrawal et a ${ }^{35}$ and Divya et $\mathrm{al}^{36}$ correlated the reduction of Act skin irritation to its encapsulation in nanostructured lipid carriers and chitin nanogel, respectively.

Therefore, Act niosomal gel could be considered as a promising formula in improving the skin tolerability and topical delivery of Act as well as patient acceptability with a high safety profile.

\section{Antipsoriatic activity study using mouse tail model}

In psoriatic skin, lymphocytes may alter the epidermal growth resulting in keratinocyte hyperproliferation and abnormal differentiation of apoptotic cells. ${ }^{104}$ Various experimental animal models have been developed for psoriasis, namely, asebia mouse, ${ }^{105}$ flaky skin mouse, ${ }^{106}$ ultraviolet ray-B induced photodermatitis model, ${ }^{107}$ genetically modified models of psoriasiform skin diseases, ${ }^{108}$ and mouse tail model. ${ }^{56-60}$ In this study, mouse tail model was selected to 
investigate the in vivo antipsoriatic activity of different gel formulations.

Photomicrographs of histopathologic evaluation of mouse tail skin after topical application of different gel formulations for 4 weeks are illustrated in Figure 11. The evaluation parameters including orthokeratosis (\%), drug activity (\%), and reduction in epidermal thickness (\%) are summarized in Table 8.

In the case of the control group, fully developed lesions of psoriatic skin were noticed. The skin displayed parakeratosis with thickened epidermis, where the SC retained its nuclei, with loss of keratohyaline granules in the granular cell layer, marked invagination of rete ridges into dermis, and neutrophilic infiltration around the hair follicles in dermis forming Munro abscess (Figure 11A). Similarly, in the case of the plain gel treated group, skin showed parakeratosis, where SC showed retention of nuclei, loss of keratohyaline granules in the granular cell layer, invagination of rete ridges into dermis, and dilation of blood capillaries with leukocytic infiltration in the dermis (Figure 11B). Also, a very slight

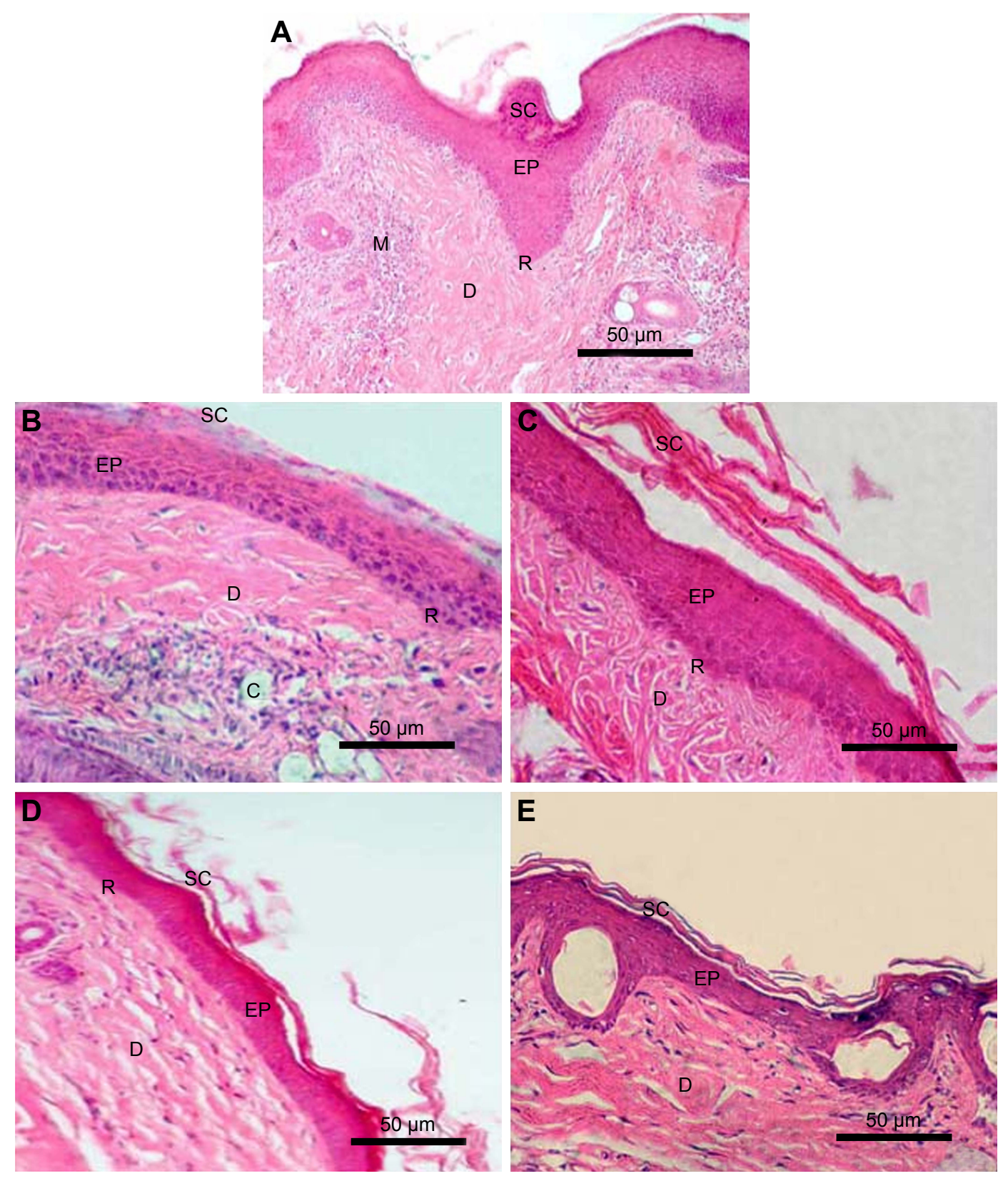

Figure I I Photomicrographs of histopathologic examination of mouse tail skin after topical application of different gel formulations for 4 weeks. Notes: (A) Control tail skin, (B) plain gel, (C) zarotex gel, (D) Act gel, and (E) Act niosomal gel. H\&E (I00x).

Abbreviations: Act, Acitretin; C, blood capillaries; D, dermis; EP, epidermis; M, Munro abscess; R, rete ridges; SC, stratum corneum. 
Table 8 Effect of different gel formulations on the degree of orthokeratosis, drug activity, and reduction in epidermal thickness in mouse tail model after topical application for 4 weeks

\begin{tabular}{|c|c|c|c|}
\hline Groups & $\begin{array}{l}\text { Orthokeratosis } \\
\text { (\%) }\end{array}$ & $\begin{array}{l}\text { Drug activity } \\
\text { (\%) }\end{array}$ & $\begin{array}{l}\text { Reduction in } \\
\text { epidermal } \\
\text { thickness (\%) }\end{array}$ \\
\hline Control (normal tail) & $11.20 \pm 2.10$ & - & - \\
\hline Plain gel & $|2.3| \pm 2.37$ & 1.25 & $9.25 \pm 2.09$ \\
\hline $\begin{array}{l}\text { Zarotex gel ( } 0.1 \% \text {; } \\
\text { commercial product) }\end{array}$ & $34.13 \pm 3.76 *$ & 25.82 & $22.64 \pm 3.08$ \\
\hline Act gel & $41.42 \pm 3.46^{*}$ & 34.03 & $59.49 \pm 3.48$ \\
\hline Act niosomal gel & $68.5 I \pm 3.22 * * *$ & 64.54 & $73.60 \pm 2.32 * *$ \\
\hline
\end{tabular}

Notes: Each value represents the mean \pm SE $(n=6) .{ }^{*} p<0.05$ vs control; $* * p<0.05$ Act niosomal gel vs other gel formulations.

Abbreviation: Act, Acitretin.

decrease in the epidermal thickness was noticed, which might be attributed to the moisturizing and emollient effects of the gel base components.

In the case of the zarotex gel-treated group, the skin exhibited parakeratosis, where SC retained its nuclei and there was loss of keratohyaline granules in the granular cell layer and moderate invagination of rete ridges (Figure 11C). The skin of the Act gel-treated group demonstrated mild orthokeratosis, where SC showed loss of nuclei, moderate loss of keratohyaline granules in the granular cell layer, mild invagination of rete ridges, and decrease in the thickness of epidermis (Figure 11D).

Interestingly, in the case of the Act niosomal gel group, the skin displayed noticeable orthokeratosis, where $\mathrm{SC}$ became cornified, most of the granular cell layers had their keratohyaline granules and there was loss of invagination of rete ridges and marked decrease in the thickness of epidermis (Figure 11E). It was noteworthy that treatment findings with Act niosomal gel were manifested by a distinguished antipsoriatic superiority with respect to significantly higher $(p<0.05)$ orthokeratosis $\%(68.51 \pm 3.22 \%)$, drug activity $\%(64.54 \%)$, and reduction in epidermal thickness $\%(73.60 \pm 2.32 \%)$ compared with the control and other gel formulations (Table 8). Our results were comparable with those of Act chitin nanogel-treated mouse tail model. ${ }^{36}$ Besides the aforementioned antipsoriatic activity of Act niosomal gel, the advantage of low production cost of niosomes on a large scale should be considered. Agrawal et al ${ }^{35}$ demonstrated the significant clinical therapeutic efficacy of Act-loaded nanostructured lipid carriers gel as a topical treatment for psoriasis. Yet, the stability of such nanolipid formula necessitates further investigation as a prerequisite for prospective commercial production.

The niosomal system has emerged as a potential approach for enhancing the topical delivery of antipsoriatic drugs, hence improving their therapeutic performance. Agarwal et $\mathrm{al}^{62}$ reported the superiority of dithranol-loaded niosomes compared with the conventional formulation using mouse skin. The potential use of niosomes for topical delivery of ammonium glycyrrhizinate was indicated by their improved anti-inflammatory and antipsoriatic activity in mice. ${ }^{109}$ As well, topical methotrexate-loaded niosomes and methotrexate niosomal chitosan gel demonstrated prospective benefits for management of psoriasis when applied to rats and human volunteers, respectively. ${ }^{110,111}$

\section{Conclusion}

This study highlights the merits of the developed Act nano niosomal gel as a promising topical delivery system with prominent enhanced permeation, drug deposition into deeper skin layers, and diminished systemic absorption. The preclinical data of the ex vivo cytotoxicity study on $\mathrm{HaCaT}$ cell line as a model of epidermal hyperproliferation in psoriasis, and in vivo antipsoriatic activity study using mouse tail model, as well as in vivo skin irritation tests have further substantiated the potentiated antipsoriatic activity of the formula with satisfactory safety profile. Consequently, clinical prospective studies are highly warranted to establish its clinical efficacy and give more insight on potential commercial production as an alternative to the currently available Act oral therapy that exhibits hazardous side effects.

\section{Disclosure}

The authors report no conflicts of interest in this work.

\section{References}

1. Brown MB, Martin GP, Jones SA, Akomeah FK. Dermal and transdermal drug delivery systems: current and future prospects. Drug Deliv. 2006; 13(3):175-187.

2. Flatz L, Conrad C. Role of T-cell-mediated inflammation in psoriasis: pathogenesis and targeted therapy. Psoriasis Target Ther. 2013;3: $1-10$.

3. Danielsen K, Olsen AO, Wilsgaard T, Furberg AS. Is the prevalence of psoriasis increasing? A 30-year follow-up of a population-based cohort. Br J Dermatol. 2013;168(6):1303-1310.

4. Michalek IM, Loring B, John SM. A systematic review of worldwide epidemiology of psoriasis. J Eur Acad Dermatol Venereol. 2017;31(2): 205-212.

5. Nickoloff BJ, Nestle FO. Recent insights into the immunopathogenesis of psoriasis provide new therapeutic opportunities. J Clin Invest. 2004; 113(12):1664-1675.

6. Lowes MA, Bowcock AM, Krueger JG. Pathogenesis and therapy of psoriasis. Nature. 2007;445(7130):866-873.

7. Pradhan M, Singh D, Singh MR. Novel colloidal carriers for psoriasis: current issues, mechanistic insight and novel delivery approaches. J Control Release. 2013;170(3):380-395.

8. Hashizume H, Ito T, Yagi H, et al. Efficacy and safety of preprandial versus postprandial administration of low-dose cyclosporin microemulsion (Neoral) in patients with psoriasis vulgaris. J Dermatol. 2007; 34(7):430-434. 
9. Clark RA. Gone but not forgotten: lesional memory in psoriatic skin. J Invest Dermatol. 2011;131(2):283-285.

10. Azfar RS, Gelfand JM. Psoriasis and metabolic disease: epidemiology and pathophysiology. Curr Opin Rheumatol. 2008;20(4):416-422.

11. Micha R, Imamura F, Wyler von Ballmoos M, et al. Systematic review and meta-analysis of methotrexate use and risk of cardiovascular disease. Am J Cardiol. 2011;108(9):1362-1370.

12. Heydendael VM, Spuls PI, Opmeer BC, et al. Methotrexate versus cyclosporine in moderate-to-severe chronic plaque psoriasis. $N$ Engl J Med. 2003;349(7):658-665.

13. Lebwohl M, Ting P, Koo J. Psoriasis treatment: traditional therapy. Ann Rheum Dis. 2005;64(Suppl 2):ii83-ii86.

14. Suresh PK, Singh P, Saraf S. Novel topical drug carriers as a tool for treatment of psoriasis: progress and advances. Afr J Pharm Pharmacol. 2013;7(5):138-147.

15. Richard EG, Hönigsmann H. Phototherapy, psoriasis, and the age of biologics. Photodermatol Photoimmunol Photomed. 2014;30(1):3-7.

16. Kofoed K, Skov L, Zachariae C. New drugs and treatment targets in psoriasis. Acta Derm Venereol. 2015;95(2):133-139.

17. Andrews SN, Jeong E, Prausnitz MR. Transdermal delivery of molecules is limited by full epidermis, not just stratum corneum. Pharm Res. 2013;30(4):1099-1109.

18. Su YH, Fang JY. Drug delivery and formulations for the topical treatment of psoriasis. Expert Opin Drug Deliv. 2008;5(2):235-249.

19. Nestle FO, Kaplan DH, Barker J. Psoriasis. N Engl J Med. 2009; 361(5):496-509.

20. Rahman M, Akhter S, Ahmad J, Ahmad MZ, Beg S, Ahmad FJ. Nanomedicine-based drug targeting for psoriasis: potentials and emerging trends in nanoscale pharmacotherapy. Expert Opin Drug Deliv. 2015;12(4):635-652.

21. Marianecci C, Di Marzio L, Rinaldi F, et al. Niosomes from 80s to present: the state of the art. Adv Colloid Interface Sci. 2014;205: 187-206.

22. Thakkar M, Brijesh S. Opportunities and challenges for niosomes as drug delivery systems. Curr Drug Deliv. 2016;13(8):1275-1289.

23. Moghassemi S, Hadjizadeh A. Nano-niosomes as nanoscale drug delivery systems: an illustrated review. J Control Release. 2014;185: 22-36.

24. Hamishehkar H, Rahimpour Y, Kouhsoltani M. Niosomes as a propitious carrier for topical drug delivery. Expert Opin Drug Deliv. 2013; 10(2):261-271.

25. Kumar GP, Rajeshwarrao P. Nonionic surfactant vesicular systems for effective drug delivery-an overview. APSB. 2011;1(4):208-219.

26. Arora R, Jain CP. Advances in niosome as a drug carrier: a review. AJP. 2007;1(1):29-39.

27. Pilkington T, Brogden RN. Acitretin: a review of its pharmacology and therapeutic use. Drugs. 1992;43(4):597-627.

28. Surber C, Laugier JP, Geiger JM, Bun H, Durand A, Maibach HI. High-performance liquid chromatography determination of acitretin in plasma and its application to a pharmacokinetic study in human subjects. Pharm Res. 1992;9(10):1365-1369.

29. Carretero G, Ribera M, Belinchón I, et al. Guidelines for the use of acitretin in psoriasis. Actas Dermosifiliogr. 2013;104(7):598-616.

30. Katz HI, Waalen J, Leach EE. Acitretin in psoriasis: an overview of adverse effects. J Am Acad Dermatol. 1999;41(3 Pt 2):S7-S12.

31. Surber C, Wilhelm KP, Bermann D, Maibach HI. In vivo skin penetration of acitretin in volunteers using three sampling techniques. Pharm Res. 1993;10(9):1291-1294.

32. Dunn LK, Gaar LR, Yentzer BA, O'Neill JL, Feldman SR. Acitretin in dermatology: a review. J Drugs Dermatol. 2011;10(7):772-782.

33. Pastuszka M, Kaszuba A. Acitretin, a systemic retinoid for the treatment of psoriasis-current state of knowledge. Post Dermatol Alergol. 2011;4:285-292.

34. Loftsson T, Sigurđardóttir AM, Ólafsson JH. Improved acitretin delivery through hairless mouse skin by cyclodextrin complexation. Int J Pharm. $1995 ; 115(2): 255-258$.
35. Agrawal Y, Petkar KC, Sawant KK. Development, evaluation and clinical studies of Acitretin loaded nanostructured lipid carriers for topical treatment of psoriasis. Int J Pharm. 2010;401(1-2):93-102.

36. Divya G, Panonnummal R, Gupta S, Jayakumar R, Sabitha M. Acitretin and aloe-emodin loaded chitin nanogel for the treatment of psoriasis. Eur J Pharm Biopharm. 2016;107:97-109.

37. Baillie AJ, Florence AT, Hume LR, Muirhead GT, Rogerson A. The preparation and properties of niosomes non-ionic surfactant vesicles. J Pharm Pharmacol. 1985;37(12):863-868.

38. Azeem A, Ahmad FJ, Khan ZI, Talegaonkar S. Nonionic surfactant vesicles as a carrier for transdermal delivery of frusemide. $J$ Dispers Sci Technol. 2008;29(5):723-730.

39. Mokhtar M, Sammour OA, Hammad MA, Megrab NA. Effect of some formulation parameters on flurbiprofen encapsulation and release rates of niosomes prepared from proniosomes. Int J Pharm. 2008; 361(1-2):104-111.

40. Fang JY, Hong CT, Chiu WT, Wang YY. Effect of liposomes and niosomes on skin permeation of enoxacin. Int J Pharm. 2001;219(1-2): 61-72.

41. Ruckmani K, Jayakar B, Ghosal SK. Nonionic surfactant vesicles (niosomes) of cytarabine hydrochloride for effective treatment of leukemias: encapsulation, storage, and in vitro release. Drug Dev Ind Pharm. 2000;26(2):217-222.

42. Hu C, Rhodes DG. Proniosomes: a novel drug carrier preparation. Int J Pharm. 1999;185(1):23-35.

43. Sloan KB, Beall HD, Weimar WR, Villanueva R. The effect of receptor phase composition on the permeability of hairless mouse skin in diffusion cell experiments. Int J Pharm. 1991;73(2):97-104.

44. Jacobsen J. Buccal iontophoretic delivery of atenolol $\mathrm{HCl}$ employing a new in vitro three-chamber permeation cell. J Control Release. 2001;70(1-2):83-95.

45. El-Kattan AF, Asbill CS, Michniak BB. The effect of terpene enhancer lipophilicity on the percutaneous permeation of hydrocortisone formulated in HPMC gel systems. Int J Pharm. 2000;198(2):179-189.

46. Gurrapu A, Jukanti R, Bobbala SR, Kanuganti S, Jeevana JB. Improved oral delivery of valsartan from maltodextrin based proniosome powders. Adv Powder Technol. 2012;23(5):583-590.

47. Goyal G, Garg T, Malik B, Chauhan G, Rath G, Goyal AK. Development and characterization of niosomal gel for topical delivery of benzoyl peroxide. Drug Deliv. 2015;22(8):1027-1042.

48. Manconi M, Sinico C, Valenti D, Lai F, Fadda AM. Niosomes as carriers for tretinoin. III. A study into the in vitro cutaneous delivery of vesicle-incorporated tretinoin. Int J Pharm. 2006;311(1-2):11-19.

49. Higuchi T. Mechanism of sustained-action mediation. Theoretical analysis of rate of release of solid drugs dispersed in solid matrices. J Pharm Sci. 1963;52:1145-1149.

50. Korsmeyer RW, Gurny R, Doelker E, Buri P, Peppas NA. Mechanisms of solute release from porous hydrophilic polymers. Int J Pharm. 1983;15(1):25-35.

51. Ritger PL, Peppas NA. A simple equation for description of solute release I. Fickian and non-Fickian release from non-swellable devices in the form of slabs, spheres, cylinders or discs. J Control Release. 1987; 5(1):23-36.

52. Mady FM, Shaker MA. Enhanced anticancer activity and oral bioavailability of ellagic acid through encapsulation in biodegradable polymeric nanoparticles. Int J Nanomedicine. 2017;12:7405-7417.

53. Shaker DS, Shaker MA, Hanafy MS. Cellular uptake, cytotoxicity and in vivo evaluation of Tamoxifen citrate loaded niosomes. Int J Pharm. 2015;493(1-2):285-294.

54. Draize JH, Woodard G, Calvery HO. Methods for the study of irritation and toxicity of substances applied topically to the skin and mucous membranes. J Pharmacol Exp Ther. 1944;82(3):377-390.

55. Manosroi A, Chankhampan C, Manosroi W, Manosroi J. Transdermal absorption enhancement of papain loaded in elastic niosomes incorporated in gel for scar treatment. Eur J Pharm Sci. 2013;48(3): 474-483. 
56. Nagle A, Goyal AK, Kesarla R, Murthy RR. Efficacy study of vesicular gel containing methotrexate and menthol combination on parakeratotic rat skin model. J Liposome Res. 2011;21(2):134-140.

57. Singhal M, Kansara N, Cassia tora L. Creams inhibit psoriasis in mouse tail model. Pharm Crop. 2012;3:1-6.

58. Laxmi RJ, Karthikeyan R, Srinivasa Babu P, Narendra Babu RVV. Formulation and evaluation of antipsoriatic gel using natural excipients. $J$ Acute Dis. 2013;2(2):115-121.

59. Vijayalakshmi A, Ravichandiran V, Velraj M, et al. Anti-Psoriatic activity of smilax china linn. rhizome. IJPER. 2013;47(1):82-89.

60. Khurana S, Jain NK, Bedi PM. Nanostructured lipid carriers based nanogel for meloxicam delivery: mechanistic, in vivo and stability evaluation. Drug Dev Ind Pharm. 2015;41(8):1368-1375.

61. Uchegbu IF, Vyas SP. Non-ionic surfactant based vesicles (niosomes) in drug delivery. Int J Pharm. 1998;172(1-2):33-70.

62. Agarwal R, Katare OP, Vyas SP. Preparation and in vitro evaluation of liposomal/niosomal delivery systems for antipsoriatic drug dithranol. Int J Pharm. 2001;228(1-2):43-52.

63. Devaraj GN, Parakh SR, Devraj R, Apte SS, Rao BR, Rambhau D. Release studies on niosomes containing fatty alcohols as bilayer stabilizers instead of cholesterol. J Colloid Interface Sci. 2002;251(2): 360-365

64. El-Menshawe SF, Hussein AK. Formulation and evaluation of meloxicam niosomes as vesicular carriers for enhanced skin delivery. Pharm Dev Technol. 2013;18(4):779-786.

65. El-Samaligy MS, Afifi NN, Mahmoud EA. Increasing bioavailability of silymarin using a buccal liposomal delivery system: preparation and experimental design investigation. Int J Pharm. 2006; 308(1-2):140-148.

66. Lingan MA, Sathali AAH, Kumar MRV, Gokila A. Formulation and evaluation of topical drug delivery system containing clobetasol propionate niosomes. Sci Revs Chem Commun. 2011;1(1):7-17.

67. Fathalla D, Abdel-Mageed A, Abdel-Hamid F, Ahmed M. In vitro and in vivo evaluation of niosomal gel containing aceclofenac for sustained drug delivery. IJPSR. 2014;1:1-11.

68. Zaki RM, Ali AA, El Menshawe SF, AbdelBary A. Formulation and in vitro evaluation of diacerein loaded niosomes. Int J Pharm Pharm Sci. 2014;6(Supp1 2):515-521.

69. Verma DD, Verma S, Blume G, Fahr A. Particle size of liposomes influences dermal delivery of substances into skin. Int J Pharm. 2003 258(1-2):141-151.

70. Gupta R, Gupta M, Mangal S, Agrawal U, Vyas SP. Capsaicin-loaded vesicular systems designed for enhancing localized delivery for psoriasis therapy. Artif Cells Nanomed Biotechnol. 2016;44(3):825-834.

71. Lasoń E, Sikora E, Ogonowski J. Influence of process parameters on properties of Nanostructured Lipid Carriers (NLC) formulation. Acta Biochim Pol. 2013;60(4):773-777.

72. Reddy LH, Murthy RS. Etoposide-loaded nanoparticles made from glyceride lipids: formulation, characterization, in vitro drug release, and stability evaluation. AAPS PharmSciTech. 2005;6(2):E158-E166.

73. Sarmento B, Ferreira D, Veiga F, Ribeiro A. Characterization of insulinloaded alginate nanoparticles produced by ionotropic pre-gelation through DSC and FTIR studies. Carbohydr Polym. 2006;66(1):1-7.

74. Sezgin-Bayindir Z, Yuksel N. Investigation of formulation variables and excipient interaction on the production of niosomes. AAPS PharmSciTech. 2012;13(3):826-835.

75. Rahman SA, Abdelmalak NS, Badawi A, Elbayoumy T, Sabry N, El Ramly A. Formulation of tretinoin-loaded topical proniosomes for treatment of acne: in vitro characterization, skin irritation test and comparative clinical study. Drug Deliv. 2015;22(6):731-739.

76. Jadon PS, Gajbhiye V, Jadon RS, Gajbhiye KR, Ganesh N. Enhanced oral bioavailability of griseofulvin via niosomes. AAPS PharmSciTech. 2009;10(4):1186-1192.

77. Kumar G, Karthik L, Rao KVB. Antimicrobial activity of latex of calotropis gigantea against pathogenic microorganisms. An in vitro study. PhOL. 2010;3:155-163.
78. Ali MF, Salem HF, Abdelmohsen HF, Attia SK. Preparation and clinical evaluation of nano-transferosomes for treatment of erectile dysfunction. Drug Des Devel Ther. 2015;9:2431-2447.

79. Abdellatif AA, Tawfeek HM. Transfersomal nanoparticles for enhanced transdermal delivery of clindamycin. AAPS PharmSciTech. 2016;17(5): 1067-1074.

80. Wu H, Liu Z, Peng J, et al. Design and evaluation of baicalin-containing in situ pH-triggered gelling system for sustained ophthalmic drug delivery. Int J Pharm. 2011;410(1-2):31-40.

81. Ogiso T, Niinaka N, Iwaki M. Mechanism for enhancement effect of lipid disperse system on percutaneous absorption. J Pharm Sci. 1996;85(1): 57-64

82. Barry BW. Novel mechanisms and devices to enable successful transdermal drug delivery. Eur J Pharm Sci. 2001;14(2):101-114.

83. Kilfoyle BE, Sheihet L, Zhang Z, Laohoo M, Kohn J, MichniakKohn BB. Development of paclitaxel-TyroSpheres for topical skin treatment. J Control Release. 2012;163(1):18-24.

84. Barakat HS, Darwish IA, El-Khordagui LK, Khalafallah NM. Development of naftifine hydrochloride alcohol-free niosome gel. Drug Dev Ind Pharm. 2009;35(5):631-637.

85. Abu Hashim II, El-Dahan MS, Yusif RM, Abd-ElGawad AH, Arima H Potential use of niosomal hydrogel as an ocular delivery system for atenolol. Biol Pharm Bull. 2014;37(4):541-551.

86. Paolino D, Cosco D, Muzzalupo R, Trapasso E, Picci N, Fresta M. Innovative bola-surfactant niosomes as topical delivery systems of 5-fluorouracil for the treatment of skin cancer. Int J Pharm. 2008; 353(1-2):233-242.

87. Shaikh K, Pawar A, Aphale S, Moghe A. Effect of vesicular encapsulation on in vitro cytotoxicity of ciclopirox olamine. Int J Drug Deliv. 2012;4(2):139-146.

88. Zarei M, Norouzian D, Honarvar B, Mohammadi M, Shamabadi HE, Akbarzadeh A. Paclitaxel loaded niosome nanoparticle formulation prepared via reverse phase evaporation method: an in vitro evaluation. Pak J Biol Sci. 2013;16(6):295-298.

89. Un RN, Barlas FB, Yavuz M, et al. Phyto-Niosomes: in vitro assessment of the novel nanovesicles containing marigold extract. Int J Polym Mater. 2015;64(17):927-937.

90. Zhang Y, Zhang K, Wu Z, et al. Evaluation of transdermal salidroside delivery using niosomes via in vitro cellular uptake. Int J Pharm. 2015 478(1):138-146.

91. LeMotte PK, Keidel S, Apfel CM. Characterization of synthetic retinoids with selectivity for retinoic acid or retinoid X nuclear receptors. Biochim Biophys Acta. 1996;1289(2):298-304.

92. Chandraratna RA. Rational design of receptor-selective retinoids. J Am Acad Dermatol. 1998;39(4 Pt 2):S124-S128.

93. Diaz BV, Lenoir MC, Ladoux A, Frelin C, Démarchez M, Michel S. Regulation of vascular endothelial growth factor expression in human keratinocytes by retinoids. J Biol Chem. 2000;275(1):642-650.

94. Pfhal M. The molecular mechanism of retinoid action-retinoids today and tomorrow. Retinoid Dermatol. 1996;44:2-6.

95. Saurat JH. Retinoids and psoriasis: novel issues in retinoid pharmacology and implications for psoriasis treatment. J Am Acad Dermatol. 1999;41(3 Pt 2):S2-S6.

96. Armstrong JL, Ruiz M, Boddy AV, Redfern CPF, Pearson ADJ, Veal GJ. Increasing the intracellular availability of all-trans retinoic acid in neuroblastoma cells. Br J Cancer. 2005;92(4):696-704.

97. Elder JT, Aström A, Pettersson U, et al. Retinoic acid receptors and binding proteins in human skin. J Invest Dermatol. 1992; 98(6 Suppl):S36-S41.

98. Mucida D, Park Y, Kim G, et al. Reciprocal TH17 and regulatory T-cell differentiation mediated by retinoic acid. Science. 2007;317(5835): 256-260.

99. Werner B, Bresch M, Brenner FM, Lima HC. Comparative study of histopathological and immunohistochemical findings in skin biopsies from patients with psoriasis before and after treatment with acitretin. J Cutan Pathol. 2008;35(3):302-310. 
100. Niu X, Cao W, Ma H, Feng J, Li X, Zhang X. Acitretin exerted a greater influence on T-helper (Th) 1 and Th17 than on Th2 cells in treatment of psoriasis vulgaris. J Dermatol. 2012;39(11):916-921.

101. Guenther LC. Topical tazarotene therapy for psoriasis, acne vulgaris, and photoaging. Skin Therapy Lett. 2002;7(3):1-4.

102. Thielitz A, Gollnick H. Topical retinoids in acne vulgaris: update on efficacy and safety. Am J Clin Dermatol. 2008;9(6):369-381.

103. Dubey A, Prabhu P, Kabrawala H, Ghate V. Niosomal gel of Adapalene: its formulation, physicochemical properties and evaluation for mildacne. Adv Biomed Pharma. 2015;2(1):22-31.

104. Barker JN. The pathophysiology of psoriasis. Lancet. 1991;338(8761): 227-230.

105. Gudjonsson JE, Johnston A, Dyson M, Valdimarsson H, Elder JT. Mouse models of psoriasis. J Invest Dermatol. 2007;127(6):1292-1308.

106. Pal HC, Chamcheu JC, Adhami VM, et al. Topical application of delphinidin reduces psoriasiform lesions in the flaky skin mouse model by inducing epidermal differentiation and inhibiting inflammation. Br J Dermatol. 2015;172(2):354-364.
107. Nakaguma H, Kambara T, Yamamoto T. Rat ultraviolet ray B photodermatitis: an experimental model of psoriasis vulgaris. Int J Exp Pathol. 1995;76(1):65-73.

108. Soboleva AG, Mezentsev AV, Bruskin SA. [Genetically modified animals as model systems of psoriasis]. Mol Biol (Mosk). 2014;48(4): 587-599. Russian.

109. Marianecci C, Rinaldi F, Mastriota M, et al. Anti-inflammatory activity of novel ammonium glycyrrhizinate/niosomes delivery system: human and murine models. J Control Release. 2012;164(1):17-25.

110. Abdelbary AA, AbouGhaly MH. Design and optimization of topical methotrexate loaded niosomes for enhanced management of psoriasis: application of Box-Behnken design, in vitro evaluation and in vivo skin deposition study. Int J Pharm. 2015;485(1-2): 235-243.

111. Lakshmi PK, Devi GS, Bhaskaran S, Sacchidanand S. Niosomal methotrexate gel in the treatment of localized psoriasis: phase I and phase II studies. Indian J Dermatol Venereol Leprol. 2007;73(3): 157-161. 


\section{Supplementary material}

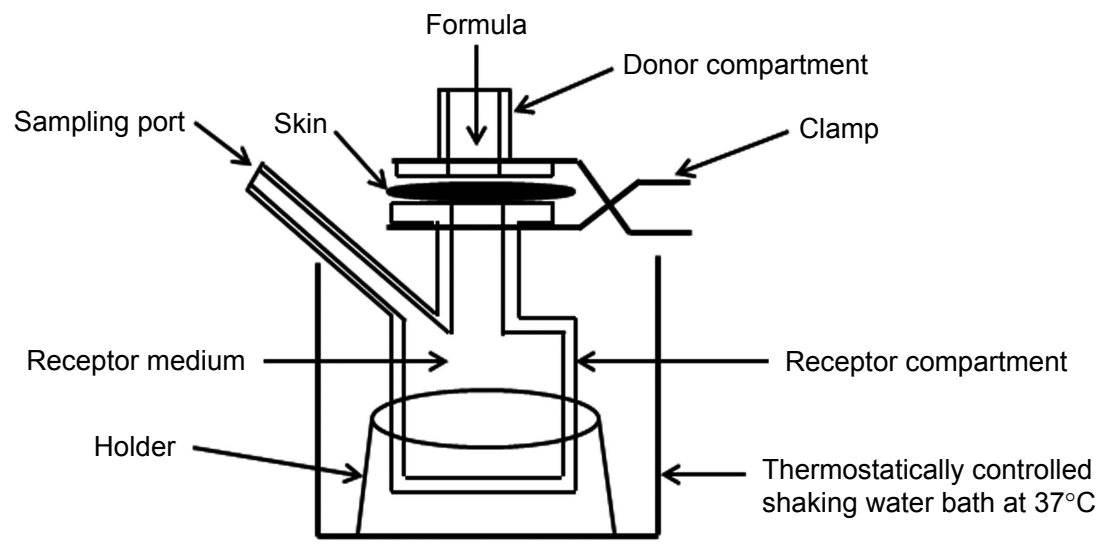

Figure SI Schematic diagram of the skin permeation measurement apparatus.

\section{Publish your work in this journal}

The International Journal of Nanomedicine is an international, peerreviewed journal focusing on the application of nanotechnology in diagnostics, therapeutics, and drug delivery systems throughou the biomedical field. This journal is indexed on PubMed Central, MedLine, CAS, SciSearch $®$, Current Contents $® /$ Clinical Medicine,
Journal Citation Reports/Science Edition, EMBase, Scopus and the Elsevier Bibliographic databases. The manuscript management system is completely online and includes a very quick and fair peer-review system, which is all easy to use. Visit http://www.dovepress.com/ testimonials.php to read real quotes from published authors.

\footnotetext{
Submit your manuscript here: http://www.dovepress.com/international-journal-of-nanomedicine-journal
} 